\title{
A toolbox of genes, proteins, metabolites and promoters for improving drought tolerance in soybean includes the metabolite coumestrol and stomatal development genes
}

\author{
Prateek Tripathi ${ }^{1,6 \dagger}$, Roel C. Rabara ${ }^{1,7 \dagger}$, R. Neil Reese ${ }^{1}$, Marissa A. Miller ${ }^{2}$, Jai S. Rohila', Senthil Subramanian ${ }^{1}$,
} Qingxi J. Shen ${ }^{3}$, Dominique Morandi ${ }^{4}$, Heike Bücking ${ }^{1}$, Vladimir Shulaev ${ }^{5}$ and Paul J. Rushton ${ }^{2,8^{*}}$

\begin{abstract}
Background: The purpose of this project was to identify metabolites, proteins, genes, and promoters associated with water stress responses in soybean. A number of these may serve as new targets for the biotechnological improvement of drought responses in soybean (Glycine max).

Results: We identified metabolites, proteins, and genes that are strongly up or down regulated during rapid water stress following removal from a hydroponics system. 163 metabolites showed significant changes during water stress in roots and 93 in leaves. The largest change was a root-specific 160-fold increase in the coumestan coumestrol making it a potential biomarker for drought and a promising target for improving drought responses. Previous reports suggest that coumestrol stimulates mycorrhizal colonization and under certain conditions mycorrhizal plants have improved drought tolerance. This suggests that coumestrol may be part of a call for help to the rhizobiome during stress. About 3,000 genes were strongly up-regulated by drought and we identified regulators such as ERF, MYB, NAC, bHLH, and WRKY transcription factors, receptor-like kinases, and calcium signaling components as potential targets for soybean improvement as well as the jasmonate and abscisic acid biosynthetic genes JMT, LOX1, and ABA1. Drought stressed soybean leaves show reduced mRNA levels of stomatal development genes including FAMA-like, MUTE-like and SPEECHLESS-like bHLH transcription factors and leaves formed after drought stress had a reduction in stomatal density of $22.34 \%$ and stomatal index of $17.56 \%$. This suggests that reducing stomatal density may improve drought tolerance. MEME analyses suggest that ABRE (CACGT/CG), CRT/DRE (CCGAC) and a novel GTGCnTGC/G element play roles in transcriptional activation and these could form components of synthetic promoters to drive expression of transgenes. Using transformed hairy roots, we validated the increase in promoter activity of GmWRKY17 and GmWRKY67 during dehydration and after $20 \mu \mathrm{M}$ ABA treatment. Conclusions: Our toolbox provides new targets and strategies for improving soybean drought tolerance and includes the coumestan coumestrol, transcription factors that regulate stomatal density, water stress-responsive WRKY gene promoters and a novel DNA element that appears to be enriched in water stress responsive promoters.
\end{abstract}

\footnotetext{
* Correspondence: wrkypaul1@gmail.com

${ }^{\dagger}$ Equal contributors

${ }^{2}$ Texas A\&M AgriLife Research and Extension Center, Dallas, TX 75252, USA

${ }^{8}$ Current address, 22nd Century Group Inc., 9530 Main Street Clarence, New York 14031, USA

Full list of author information is available at the end of the article
}

\section{Biomed Central}

(c) 2016 Tripathi et al. Open Access This article is distributed under the terms of the Creative Commons Attribution 4.0 International License (http://creativecommons.org/licenses/by/4.0/, which permits unrestricted use, distribution, and reproduction in any medium, provided you give appropriate credit to the original author(s) and the source, provide a link to the Creative Commons license, and indicate if changes were made. The Creative Commons Public Domain Dedication waiver (http://creativecommons.org/publicdomain/zero/1.0/) applies to the data made available in this article, unless otherwise stated. 


\section{Background}

Among the abiotic stresses, drought is the single greatest factor that limits global food production [1]. New targets for the potential improvement of drought responses in crop species are therefore valuable. Tolerance to drought is, however, a complex quantitative and multigenic trait that is largely controlled by small effect genes or QTLs [2-4]. There is also a significant environmental effect on water stress responses in plants and the genetic control of traits associated with tolerance to drought often shows low heritability. As a consequence, drought responses from hydroponics, growth chambers, greenhouses, and different field conditions vary. In addition, water stress in the field often occurs together with other abiotic stresses such as heat or high salinity, adding another layer of complexity. Under such field conditions, gene, protein and metabolite discovery becomes difficult because the whole system is constantly subjected to various degrees of different stresses in varying combinations.

Drought responses have previously been studied in soybean using both pot-based systems (PSys) and hydroponics systems (HSys) [5-7]. PSys are more similar to field conditions with a slower rate of water loss that allows acclimation to the stress [5]. On the other hand, the rapid stress associated with the removal of soybean plants from a hydroponics solution results in a more uniform response to the stress and this may facilitate gene, protein, and metabolite discovery. Expression profile analyses of both systems show that although there are differences, many genes appear to show similar expression characteristics, for example GmaxADC2-like and GmaxADC2-like1 [5].

Soybean is an important crop and several transcriptome analyses of the response to drought have been reported [8,9]. Chen et al. [8] reported a genome-wide transcriptional analysis of two soybean genotypes under dehydration and rehydration. They identified over one thousand differentially expressed genes (at least two fold change) and the genes primarily encoded transcription factors, protein kinases, and other regulatory proteins. Le et al. [9] used a PSys and studied soybean leaf tissue at late developmental stages under drought stress. They identified 6,500 differentially regulated genes (at least two fold change) with many upregulated genes encoding transcription factors, kinases, two-component systems or proteins with functions in abiotic stress such as late embryogenesis-abundant proteins. Neither of the two reports extended their observations beyond the transcriptome level. More recently, Shin et al. [10] studied transcriptomic changes due to water deficit in two soybean cultivars, one of which was a slow-wilting variety [10]. They found that transcriptional responses to water deficit in soybean involve not only known pathways such as down-regulation of photosynthesis but also up- regulation of processes such as protein transport and chromatin remodeling. The importance of roots and root architecture to soybean drought responses was illustrated in a recent article by Prince et al. [11]. Genetically diverse soybean germplasm lines were selected and lines $578477 \mathrm{~A}$ and 088444 had higher later root number and forks in clay soil and a higher yield under water limitation. Similarly, in sandy soil, PI 458020 had a thicker lateral root system and higher yield under water limitation [11].

Here, we use a HSys-based approach for systems level analyses and identify targets for the improvement of soybean drought tolerance. Previous analyses from soybean have not been as extensive as the data presented here that combines physiological, transcriptomic, proteomic, metabolomics, and promoter analyses from the same samples. We can therefore make direct comparisons between changes in the different levels of the system. We identified 2,972 genes that were differentially regulated in leaves and 1,394 in roots ( $\geq 8$-fold). In the same samples, we identified 95 biochemicals that show a statisically significant change in level $(p<0.05)$ in leaves and 163 biochemicals that show changes in roots. We suggest a new drought tolerance mechanism in legumes linking drought, coumestrol and mycorrhiza. We propose that drought induces an increase in coumestrol in the roots. This promotes the growth of mycorrhizal fungi, improves water use efficiency, and thereby enhances plant tolerance to drought stress. We present a toolbox for improving soybean drought tolerance consisting of targets at the gene, protein, and metabolite levels together with promoters and promoter elements for expressing transgenes. Finally, we discuss new strategies using these tools for the improvement of drought tolerance in soybean.

\section{Results}

Our aim was to produce a list of targets whose manipulation might lead to increased drought tolerance in soybean (What are we going to express?). In addition, we also sought to produce a set of tools for the expression of these transgenes (How are we going to express it?) These potential transgenes and promoters (both native and synthetic) make up a toolbox for new strategies to improve drought tolerance. The components of this toolbox are listed in Table 1 along with comparisons with similar targets from other systems.

\section{The physiological level}

In the field, it is common for plants to encounter abiotic stresses simultaneously. It is therefore difficult to characterize the signaling web that is associated with any one particular stress. Consequently, we performed experiments using hydroponic conditions where temperature, 
Table 1 Genes, proteins, metabolites, and promoters that are promising tools for the improvement of soybean drought responses

\begin{tabular}{|c|c|c|}
\hline & Tissue & Observations \\
\hline & \multirow{4}{*}{$\begin{array}{l}\text { Leaves } \\
\text { and } \\
\text { roots }\end{array}$} & Up-regulated genes \\
\hline Homeobox leucine zipper & & \multirow{3}{*}{$\begin{array}{l}\text { In leaf about } 100 \text {-fold induced after } 2 \mathrm{~h} \text { and } \\
\text { after five hours. In root about } 20 \text {-fold after fiv } \\
\text { The two proteins are } 90.2 \% \text { similar. }\end{array}$} \\
\hline GLYMA16g02390 & & \\
\hline GLYMA07g05800 & & \\
\hline ERF/AP2 & \multirow{2}{*}{$\begin{array}{l}\text { Leaves } \\
\text { and } \\
\text { roots }\end{array}$} & \multirow{2}{*}{$\begin{array}{l}\text { The most strongly up-regulated transcription } \\
\text { factor gene in leaves after two hours with an } \\
\text { inducition of } 135 \text {-fold. Induced } 36 \text {-fold after } \\
\text { one hour in roots. }\end{array}$} \\
\hline GLYMA05g32040 & & \\
\hline
\end{tabular}

ERF/AP2

GLYMA20g30840

ERF/AP2

GLYMA03g26310

ERF/AP2

GLYMA10g33810

GLYMA20g33800 (paralogs with $90.5 \%$ identity)

WRKY

GLYMA01g43130 (GmWRKY161)

WRKY

GLYMA17g04710 (GmWRKY112)

NAC

GLYMA12g22880

NAC

GLYMA12935000

bHLH

GLYMA12g22880

MYB

GLYMA05g35050

$\mathrm{C} 3 \mathrm{H}$

GLYMA06g44440 (SOMNUS)

ERF/AP2

GLYMA10g36760

JAZ/TIFY

GLYMA15909980

LEA protein
Leaves The most strongly up-regulated transcription and factor gene (573-fold after five hours in leaves). roots 10 -fold induced in roots.

Roots The third most strongly induced soybean gene at early time points in root and the most strongly up-regulated AP2/ERF gene.

Leaves 10 -fold and 23-fold induced in leaves after five hours.

Comments

\section{-}


Table 1 Genes, proteins, metabolites, and promoters that are promising tools for the improvement of soybean drought responses (Continued)

GLYMA10g07410

Glucose and ribitol dehydrogenase

GLYMA03g39870

Auxin efflux carrier

GLYMA11g09250

Cytokinin hydroxylase-like

\section{GLYMA10g37920}

Jasmonic acid carboxyl methyltransferase (JMT)

\section{GLYMA16g24800}

Lipoxygenase LOX1

GLYMA13g42320

ELI3-2 mannitol

dehydrogenase

GLYMA01g02580

ABA2 (ABA deficient 2)

GLYMA11g18570

Protein phosphatase $2 \mathrm{C}$ (similar to AIP1, HIGHLY ABAINDUCED PP2C GENE 2,

HONSU)

\section{GLYMA01g43460}

Stomatal Density and Distribution 1 (SDD1)

\section{GLYMA19g35200}

bHLH (Group 10 la)

GLYMA06g35330

GUARD CELL HYDROGEN PEROXIDE-RESISTANT1 (GHR1)

GLYMA15g13840 and

GLYMA09g02881

GmICHG

GLYMA12g05770

Coumestro $\begin{array}{ll}\text { Leaves } & \text { The most strongly up-regulated gene in the soybean } \\ \text { and } & \text { genome }(1,018 \text {-fold in leaves after three hours). Also } \\ \text { roots } & \text { up-regulated to a lower level in roots. }\end{array}$

Leaves One of only three genes induced over 1,000-fold by and drought (1,009-fold after five hours in leaf). Also

roots up-regulated to a lower level in roots.

Roots 610-fold induced in leaves.

Leaves Very rapid early induction and maximum of 60-fold and after five hours. 8-fold induction in leaves.

roots

Roots

Root-specific early induction and maximum of 237fold after five hours

Roots

Later root-specific induction with a maximum of 89 -fold after five hours.

Roots Strongly induced in both tissues with a maximum of 618-fold in leaves after five hours and 157 - fold in roots at the same time point.

Leaves 156-fold up-regulated in leaves after five hours and and 32 -fold induced in roots at the same time point.

roots

Leaves 72 -fold up-regulated in leaveas and 31-fold in roots. and

roots

\section{Down-regulated genes}

Leaves mRNA level goes down 17-fold in leaves at the earliest time point. At this time point the eighth most strongly down-regulated gene.

Leaves mRNA level goes down 31-fold in leaves after two hours. At this time point the tenth most strongly down-regulated gene.

Leaves Within $30 \mathrm{~min}$, the levels of mRNA encoding Glyma15g13840 and Glyma09g02881 fall to about one third of their non-stressed levels and reach a 79-fold reduction after 3-5 $\mathrm{h}$.

Constitutive genes

Roots Among the 170 most highly expressed genes in soybean roots

\section{Metabolites}

Roots An isoflavanoid with a striking 161-fold increase after three hours in roots. Levels have increased 46 -fold after just one hour.
LEA proteins are well known drought response genes. The massive induction of this particular LEA gene suggests it could be a useful target for soybean improvement.

May be involved in carbohydrate metabolism and the acquisition of desiccation tolerance (uniprot.org).

Role in drought responses is unknown.

This suggests that trans-hydroxylation is involved in the regulation of cytokinin metabolism and signaling.

Potential for improving drought responses unknown.

Catalyzes the formation of methyl jasmonate from jasmonic acid and is a key enzyme for jasmonateregulated plant responses (Seo et al., 200).

Involved in the biosynthesis of JA

Mannitol dehydrogenase (MTD) is a prime modulator of mannitol accumulation in plants (Zamski et al., 2001).

ABA2 is an abscisic acid biosynthesis enzyme that belongs to a family of short-chain dehydrogenases/ reductases. It is also called xanthoxin dehydrogenase. ABA2 catalyzes the conversion of xanthoxin to abscisic aldehyde. Abscisic aldehyde is then converted to ABA. ABA2 is a good candidate for improvement of soybean drought responses.

Similar to the HIGHLY ABA-INDUCED PP2C GENE 2 of Arabidopsis that functions as positive regulator of ABA (Lim et al., 2012).

Appears to be part of a long term response to drought that reduces the amount of stomata in new leaves.

Group $10 \mathrm{IA}$ bHLH gene related to the regulators of stomatal development in Arabidopsis, FAMA, SPEECHLESS, and MUTE

GHR1 mediates ABA and hydrogen peroxideregulated stomatal movement under drought stress [21] and GHR1 is a critical early component in ABA signaling.

The isoflavone conjugate-hydrolyzing $\beta$-glucosidase ( $\mathrm{Gm} / \mathrm{CHG}$ ) may release conjugated coumestrol from its latent form in the vacuole to be excreted from the roots to promote plant-microbe interactions.

Previous reports show that coumestrol stimulates mycorrhizal colonization and hyphal growth and under certain conditions mycorrhizal plants can have improved drought tolerance. Possible novel drought 
Table 1 Genes, proteins, metabolites, and promoters that are promising tools for the improvement of soybean drought responses (Continued)

Formononetin $\begin{aligned} & \text { An isoflavanoid that increases almost 10-fold in } \\ & \text { roots. }\end{aligned}$
Allantoin
$\begin{array}{ll}\text { Leaves } & \text { Allantoin levels increase nearly 8-fold in leaves and } \\ \text { and } & 4.2 \text {-fold in roots. } \\ \text { roots }\end{array}$

Raffinose

Galactinol

y-aminobutyrate (GABA)

JA (Jasmonate)

Ethylene (Ethene)

MAP kinase 2-like

GLYMA05g37480

Inositol-polyphosphate 5phosphatase

GLYMA07g40360

ABRE CACGT/CG
Leaves In the roots there is a large increase in raffinose after and three and five hours, reaching a peak of 12.89-fold roots increase after five hours of drought. A similar rise in leaves reaches 21.8-fold after five hours.

Leaves In the leaf, galactinol increases 9.6-fold but there is no significant increase in roots.

Roots GABA levels increase 13-fold in roots.

Hormones

Leaves The ABA concentration increased 7.8-fold after five and hours in leaf tissue and appears to increase over 5roots fold in roots. Strong $A B A 2$ up-regulation is consistent with increasing ABA levels. Many ABA responsive genes are up-regulated in both tissues. Components of $\mathrm{ABA}$ signaling such as protein phosphatase $2 \mathrm{C}$ genes are also up-regulated.

Roots There was a rapid rise in JA and its biologically active conjugate JA-ILE in the roots All of the biosynthetic enzyme genes in the JA biosynthetic pathway are rapidly and coordinately up-regulated in roots. Many JA signaling components such as JAZ repressors are differentially regulated.

Leaves Cyanoalanine (an indicator of ethylene biosynthesis) and was elevated at the earliest time-point in leaf tissue roots suggesting that ethylene plays an early role in the response. The biosynthetic enzyme genes in the ethylene biosynthetic pathway show up-regulation. Proteins

Leaves Increases 3.63-fold at the protein level.

Leaves Increases 3.63-fold at the protein level.

Promoters

Leaves The well-characterized ABA Response Element is and found in the promoters of many of the most roots strongly up-regulated genes and the ABREs are clustered in the first 250-500 bp of the promoters. tolerance mechanism where drought induces an increase in coumestrol, increased interactions with mycorrhiza and thereby enhances tolerance to drought stress. Coumestrol is therefore a potential biomarker for water stress and a promising target for legume improvement.

Like coumestrol, formononetin may be involved in signaling to the rhizosphere as a response to drought.

The purine metabolite allantoin enhances abiotic stress tolerance through synergistic activation of abscisic acid metabolism [17]. Mutants that accumulate more allantoin show enhanced tolerance to drought.

The raffinose pathway can provide osmolytes in situations of low water potential.

Galactinol acts as an osmolyte in situations of low water potential.

The GABA shunt is a stress response pathway, the functions of which include controlling cytoplasmic $\mathrm{pH}$, maintaining $\mathrm{C} / \mathrm{N}$ balance by converting glutamate in the cytosol to succinate in the TCA cycle, and aiding in oxidative stress protection by generating NADH and succinate.

ABA plays a central role in regulating drought responses in soybean.

JA clearly plays an important role in the response to drought in soybean. Lipoxygenase, allene oxidase synthase, allene oxidase cyclase, and 12-Oxo-PDA-reductase genes all show induction in roots and may be good targets for improvement of soybean.

Ethylene plays a role in the regulation of drought responses.

Similar proteins in Medicago truncatula and Arabidopsis respond to many different stress stimuli.

A similar Arabidopsis protein (AT1G05630) is induced in response to $A B A$ and wounding treatments.

The ABRE is a binding site for certain members of the bHLH and bZIP transcription factor families. Synthetic promoters containing ABREs or ABREs in combination with other drought responsive elements may prove useful for driving transgenes in projects aimed at improving drought responses. 
Table 1 Genes, proteins, metabolites, and promoters that are promising tools for the improvement of soybean drought responses (Continued)

$\begin{array}{ll}\text { CRT/DRE motif CAC/TCGACC } & \begin{array}{l}\text { Leaves } \\ \text { and } \\ \text { roots }\end{array}\end{array} \begin{aligned} & \text { Found in ten of the root early up-regulated } \\ & \text { promoters }\end{aligned}$

GTGCnTGC/G Element

GmWRKY71 and GmWRKY67

promoters

GmWRKY53 and GmWRKY112 promoters
Leaves Found by MEME in found in sixteen of the leaf late up-regulated promoters

Roots

Drought inducible. The GmWRKY17 promoter is also responsive to $A B A$.

Roots Drought inducible. GmWRKY53 and -112 promoters and respond positively to water stress through $\begin{array}{ll}\text { and } & \text { respond positively to water stress through } \\ \text { leaves } & \text { exogenous application of salt and PEG. }\end{array}$

\begin{abstract}
The Cold/Dehydration Responsive Element is the
binding site for AP2/ERF transcription factors. Given that many ERF genes are strongly up-regulated by drought and that several are listed in this table as potential targets for improving drought responses then their potential binding sites are excellent candidates for building blocks for synthetic drought-inducible promoters.
\end{abstract}

Novel potential element. Will require detailed functional characterization and identification of cognate transcription factors.

Drought and cold inducible promoters.

Drought and salt inducible promoters. relative humidity, and the light regime were controlled. This minimized the effect of abiotic stresses other than water deficit. Soybean plants were subjected to a rapid and uniform water deficit stress by removing the plants from the hydroponics solution by means of the pots. In this way, wound responses were avoided by not touching the plants and harvesting was achieved quickly. A time course of five hours was chosen because five hour dehydrated plants were still able to recover and re-grow when put back into the hydroponics solution, showing that plant death had not occurred. To monitor the extent of the response to water stress physiological parameters were monitored. In roots, an 11 \% decrease in total water content (\%TWC) from 3-5 h of dehydration was observed while a $10 \%$ decrease in leaves \%TWC from $2-5 \mathrm{~h}$ was observed (Fig. 1). This observation is accordance with the similar trends seen in experiments performed in soil [12]. The osmotic potential showed a similar trend. In contrast, stomatal conductance revealed rapid stomatal closure within 30 min (Fig. 1). The stomatal conductance dropped to about one third of the control level by $30 \mathrm{~min}$ and after $2 \mathrm{~h}$, the stomata were essentially closed.

In addition, the levels of the phytohormones abscisic acid (ABA), jasmonate (JA), jasmonate-isoleucine (JAILE), and salicylic acid (SA) were determimed. The most notable response was a rapid rise in JA and its biologically active conjugate JA-ILE in the roots (Fig. 1). In leaves there was a strong increase in ABA levels starting after one hour of drought. The increase in roots was less than in leaves (Fig. 1). This greater increase in ABA levels in leaves was mirrored by a 156-fold up-regulation in leaves and 32-fold induction in roots of the abscisic acid biosynthesis gene ABA2 (GLYMA11g18570). ABA2 catalyzes the conversion of xanthoxin to abscisic aldehyde. Abscisic aldehyde is then converted to ABA. $A B A 2$ is therefore a candidate for the manipulation of soybean drought responses (Table 1). SA levels rose slightly in roots but showed a large spike in level in leaves between one and five hours. Cyanoalanine (an indicator of ethylene biosynthesis) was elevated at the earliest time-point in leaf tissue suggesting that ethylene also plays an early role in the response.

\section{The metabolome level}

To determine metabolite responses samples were analyzed by liquid chromatography/mass spectrometry (LC/ MS, LC/MS2) and gas chromatography/mass spectrometry (GC/MS) platforms. 207 biochemicals were detected in the root tissue and 241 in leaf tissue. Changes in the biochemical profile of root were far more extensive than those observed in leaf (Additional file 1: Table S1). The changes were also faster because statistically significant changes were only observed in leaf after $120 \mathrm{~min}$. This is similar to the transcriptome data in leaf where there were no significant changes at the earliest two time points (see below).

Previous studies have shown that sugars (such as raffinose family oligosaccharides, sucrose, trehalose and sorbitol), sugar alcohols, amino acids, and amines accumulate under drought stress [13]. These function as osmolytes because they can accumulate to high concentrations within cells without impairing cellular function [14]. Starting at one hour, an increase in many sugars was observed in roots including trehalose, raffinose, mannitol, pinitol, sucrose and kestose. In leaves, trehalose was not detected and pinitol did not increase. In both roots and leaves, the most predominant accumulated sugars were raffinose and galactinol (Additional file 2: Figure S1).

Amino acids can also act as compatible solutes or osmolytes. Both leaves and roots accumulated various amino acids but increases were greater and induction faster in roots than in leaf material. In roots there was a steady increase in most amino acids from the $30 \mathrm{~min}$ 

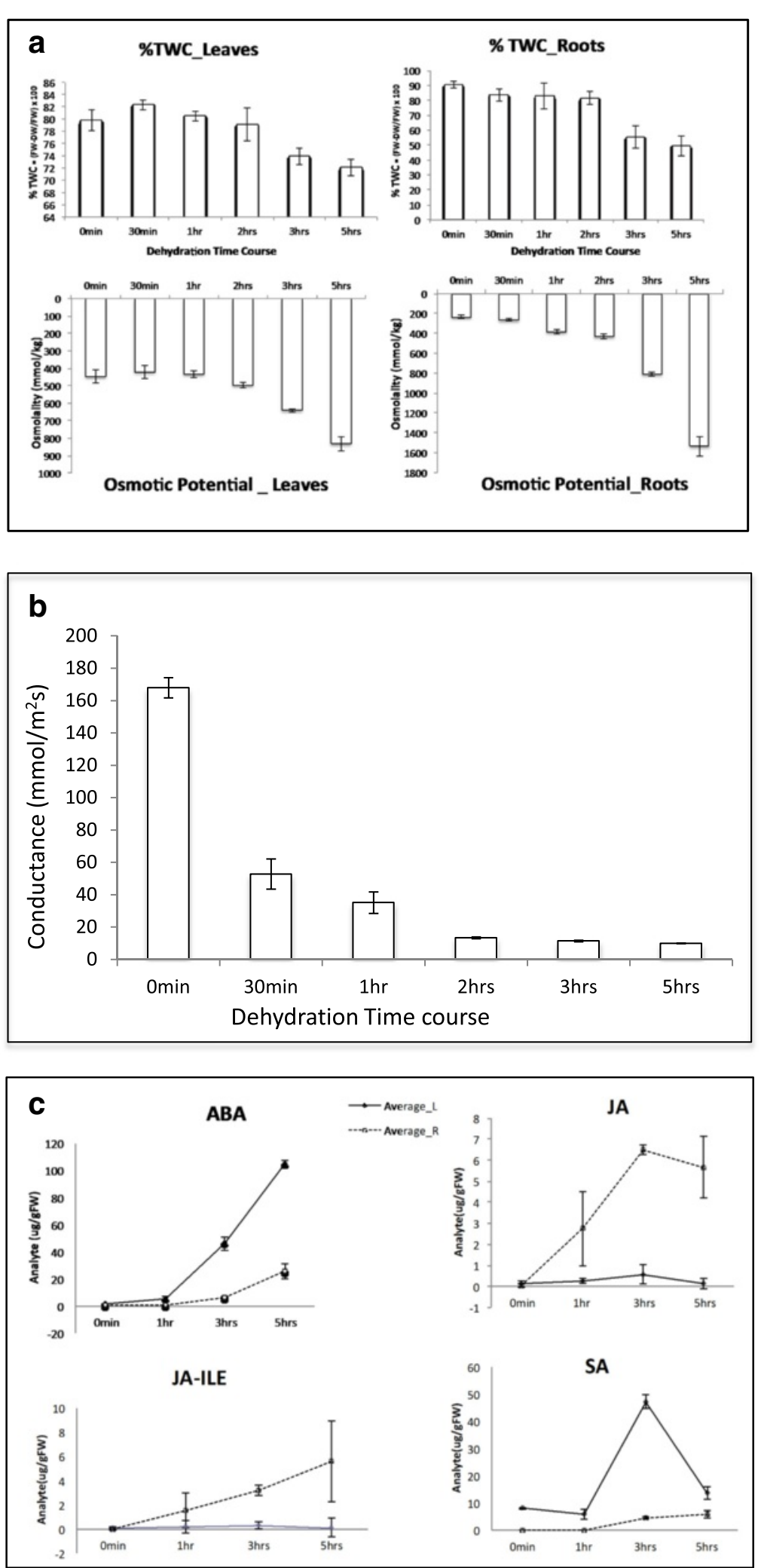

Fig. 1 Physiological responses during water stress. a Total water content and osmotic potential. b Stomata conductance. c Phytohormone levels. Error bars show mean \pm standard error for nine independent plants for each time point. Leaf is denoted by a solid line and root by a dotted one 
time point to five hours. In contrast, in leaf only lysine and alanine were higher after $30 \mathrm{~min}$ and $1 \mathrm{~h}$ although most amino acids were higher by $5 \mathrm{~h}$ (Fig. 2). In roots, glycine, histidine, isoleucine, leucine, and valine all increased at least 10 fold.

Ammonia detoxification appears to be occurring and the conversion of ammonia into non-toxic forms appears critical in maintaining normal cellular functions during water stress $[15,16]$. One early response was the accumulation of asparagine, allantoin and glutamine (Additional file 3: Figure S2). Asparagine and allantoin are the main metabolites responsible for nitrogen storage and transport. Glutamine is produced by the initial assimilation of ammonia by the action of glutamine synthetase. Recently, it has been demonstrated that the purine metabolite allantoin enhances abiotic stress tolerance through synergistic activation of abscisic acid metabolism [17]. Mutants that accumulate more allantoin show enhanced tolerance to drought. In our experiments, allantoin levels increased nearly 8 -fold in leaves and 4.2 -fold in roots. This identifies allantoin as a potential target for the improvement of soybean (Additional file 1: Table S1).

\section{Coumestrol and a possible drought tolerance mechanism}

The most dramatic observation at the metabolite level was a tissue-specific accumulation of various isoflavonoids in roots (Fig. 3). The greatest induction of any detected compound was seen with coumestrol, with a striking 160fold increase after three hours (Fig. 2 and Additional file 1: Table S1). Several isoflavones, such as daidzein and formononetin, have been reported to play roles in signaling and communication in rhizosphere plant-microbe interactions $[18,19]$. In our study, daidzein shows only a two fold increase whereas formononetin levels increase about 8.5fold. The intermediate for both formononetin and coumestrol, daidzein, does not increase suggesting that the major flux in soybean roots during drought is through the pathway that leads to coumestrol with less flux through the pathway that leads to formononetin. Our results therefore suggest a link between drought and coumestrol in legumes. Drought induces a large increase in coumestrol in the roots. We hypothesize that this increase promotes the growth of mycorrhizal fungi and thereby enhances plant tolerance to drought stress. Coumestrol is therefore a potential biomarker for drought and a promising target for legume improvement (Table 1).

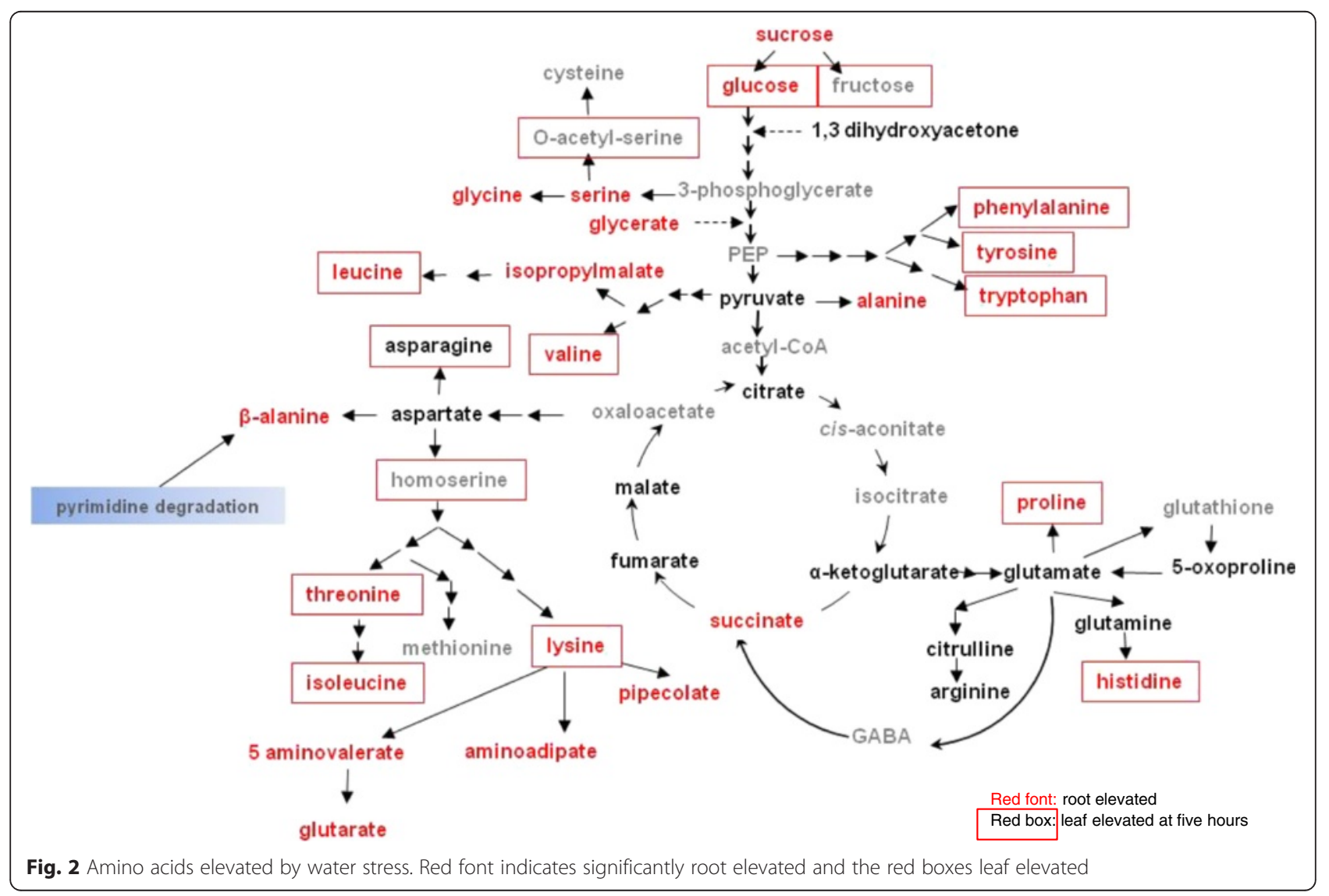


a

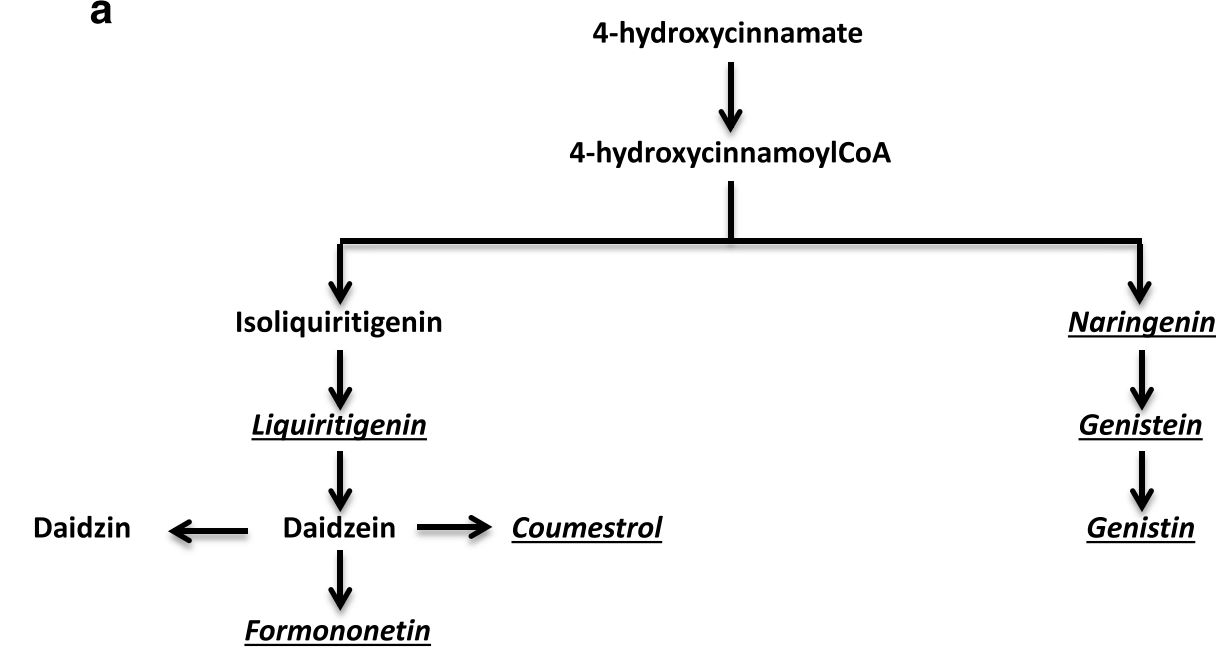

b

\begin{tabular}{|c|c|c|c|c|c|c|}
\hline & \multicolumn{5}{|c|}{ Fold Change } \\
\hline & & 30 mins & $1 \mathrm{~h}$ & $2 \mathrm{~h}$ & $3 \mathrm{~h}$ & $5 \mathrm{~h}$ \\
\hline \multirow{9}{*}{ Flavonoids } & daidzein & 1.18 & 1.02 & 1.56 & 2.12 & 1.99 \\
\hline & daidzin & 0.73 & 0.59 & 1.7 & 2.19 & 0.67 \\
\hline & formononetin & 2.62 & 1.81 & 2.81 & 6.23 & 8.58 \\
\hline & genistein & 1.4 & 1.49 & 2.65 & 4.61 & 2.54 \\
\hline & genistin & 1.59 & 2.44 & 3.6 & 6.16 & 4.58 \\
\hline & naringenin & 1.54 & 1.38 & 2.01 & 4.07 & 2.82 \\
\hline & syringic acid & 1.72 & 2.48 & 4.34 & 7.28 & 3.27 \\
\hline & coumestrol & 6.23 & 46.06 & 117.37 & 161.23 & 103.23 \\
\hline & liquiritigenin & 1.15 & 1.15 & 1.77 & 2.49 & 3.52 \\
\hline
\end{tabular}

Fig. 3 Isoflavonoid biosynthesis in roots during drought. a The biosynthetic pathway leading to coumestrol, formononetin, and genistin. Underlined and italicized indicates statistically significant increases in concentration. b Heat map of statistically significant changes in isoflavonoids. Red cells indicate $p \leq 0.05$ with the mean values significantly higher than the control. Light red cells indicate $0.05<p<0.10$

The transcriptome level

To find targets at the mRNA level for improving drought tolerance genome-wide transcriptome profiles were generated using a custom designed oligoarray containing probes for all gene models from v1.0 of the soybean genome. Three biological replicates were used. Our strategy of eliminating stresses except water deficit was validated by the large number of genes that showed high levels of differential expression. This likely reflects a lack of stress in the control plants coupled with a uniform response of the tissues. To concentrate on the mostly highly induced or repressed genes, we set a threshold of $\geq 8$-fold for differentially regulated genes. Even with this high threshold 2,972 genes were differentially expressed in leaves and 1,394 in roots. A complete list of all differentially expressed genes is presented in Additional file 4: Table S2.

Changes in mRNA levels occured more rapidly in the root than the leaves. At the earliest time-point in roots (30 $\mathrm{min}$ ), 128 genes showed at least 8-fold induction.
Using Singular Enrichment Analysis, the most significant early GO terms were transcription factor activity and transcription regulator activity (Additional file 5: Figure S3 and Additional file 6: Table S3). By five hours 1195 genes were differentially expressed and the most significant GO terms now also include downstream target gene activation (Additional file 6: Table S3, Additional file 7: Table S4, Additional file 8: Table S5).

In contrast to roots, there were no significant changes in the transcriptome in leaf in the first two hours. This is in agreement with the metabolomics data that show that changes in the biochemical profile of root tissues were far more extensive and more rapid than that observed in leaf tissues. By two hours, however, 640 genes were differentially expressed (Additional file 4: Table S2 and Additional file 5: Figure S3) and after five hours, it was clear that major transcriptional re-programming was occurring because this number had increased to 2,652, representing about $4.7 \%$ of total genes (Additional file 9: Table S6, Additional file 10: Table S7). 
The changes between two hours and five hours again illustrated a progression from signaling to downstream responses aimed at protecting the plant against drought.

One major focus of our analyses was differentially expressed transcription factors because transcription factors are good candidates for improving drought tolerance. Major differences were observed between leaves and roots in both the timing and nature of the transcription factor genes that were differentially expressed. In roots, after $30 \mathrm{~min}, 44$ of the 134 differentially regulated genes encoded transcription factors (Additional file 11: Table S8). Transcription factor gene expression in leaves (Additional file 12: Table S9) is qualitatively different from early time-points in the root. MapMan analysis suggests that ERF, WRKY, HSF, MYB, and bHLHs are the major families of up-regulated transcription factors (Fig. 4). Taken together, we see major differences between leaves and roots in both the timing and nature of the transcription factor genes that are regulated at the mRNA level. These genes represent good targets for soybean improvement (Table 1).

Several classes of genes encoding other signaling molecules show differential regulation in either leaves or roots (Additional file 4: Table S2). These data suggest that protein kinases, protein phosphatase 2Cs, F-box family proteins, and ubiquitin protein ligases all play roles. Both GO and MapMan analyses also confirmed a role for the hormones ABA, SA, and ethylene (Additional file 6: Tables S3, Additional file 7: Tables S4, Additional file 8: Tables S5, Additional file 9: Tables S6, Additional file 10: Tables S7), consistent with their observed increases. In leaves, GO analyses (Additional file 9: Table S6 and Additional file 13: Table S10) also suggest a role for calcium signaling.

Receptor-like kinases (RLKs) are important components of early signaling including drought [20]. Analysis of RLK genes reveals a marked difference between root and leaf tissue (Fig. 5). Both tissues differentially regulate many RLK genes but leaf tissues show a striking downregulation of about half of the LRR subfamily III genes (Fig. 5). Among these are Glyma15g13840 and Glyma09g02881, two soybean orthologues of the Arabidopsis GUARD CELL HYDROGEN PEROXIDERESISTANT1 (GHR1) gene. GHR1 mediates ABA and hydrogen peroxide-regulated stomatal movement under drought stress [21] and GHR1 is a critical early component in ABA signaling. Within $30 \mathrm{~min}$, the levels of mRNA encoding Glyma15g13840 and Glyma09g02881 fall to about one third of their non-stressed levels and reach a 7-9-fold reduction after 3-5 h (Additional file 4: Table S2). This parallels a similar rapid drop in stomatal conductance. These data identify the soybean orthologs of GHR1 as potential targets for improving drought tolerance via their effect on stomatal movement.
At the later time-points, downstream genes encoding proteins that protect the cell from the effects of water deficit showed increasing induction. These include water channel proteins, membrane transporters, proteins that protect and stabilize cell structures from damage by reactive oxygen species (detoxification enzymes such as glutathione S-transferase) and proteins that protect macromolecules (LEA, osmotin, chaperons) (Table 1 and Additional file 4: Table S2).

\section{Water stress induced changes in the stomatal development program}

The soybean bHLH transcription factor family contains 38 members that were strongly up- or down-regulated by drought and this response was markedly tissue specific (Additional file 14: Table S11). In roots the majority of genes were up-regulated. Interestingly, the picture in leaves was the opposite, with 18 out of 23 genes showing a reduction in mRNA to less than $12.5 \%$ of unstressed levels (Fig. 6). A combined phylogenetic tree of the soybean and Arabidopsis bHLH gene families revealed that there are two major clusters of leaf down-regulated bHLH genes in soybean (Additional file 15: Figure S4). Subfamily 10 (Ia) contains eight down-regulated genes and subfamily 3 (IVa) contains 6 genes. Interestingly, subfamily 10 (Ia) bHLH includes three regulators of stomatal development in Arabidopsis, FAMA, SPEECHLESS, and MUTE [22]. All three transcription factors are positive regulators of stomatal development. This prompted us to look at the soybean orthologues of these genes.

The soybean genome is a partially diploidized tetraploid [23] and therefore two soybean co-orthologs of FAMA, SPEECHLESS, and MUTE might be expected. The situation in soybean is, however, rather more complex. The three Arabidopsis bHLH transcription factors are closely related and form a clade with ten soybean bHLHs. There appear to be four co-orthologs of SPEECHLESS and two show reduction in mRNA levels of between 5- and 6.3 fold (Fig. 7). Soybean contains two co-orthologs of MUTE and one of the two MUTE-like genes shows a 9-fold drop in mRNA level. Interestingly, the two FAMA-like genes in soybean show no significant change in mRNA level. However, there are two additional soybean FAMA/SPEECHLESS/MUTE-like genes in the clade and these two genes are among the fifteen most strongly down-regulated soybean genes after three hours in leaves (out of over 50,000 expressed genes) with mRNA levels 87-fold (Glyma16g02020) and 56-fold (Glyma07g05500) less than unstressed plants (Fig. 7). Taken together, our results suggest that all three steps in the pathway that leads to the differentiation of stomata are down-regulated as a long-term response of soybean to lack of water however, the numbers and identities of 


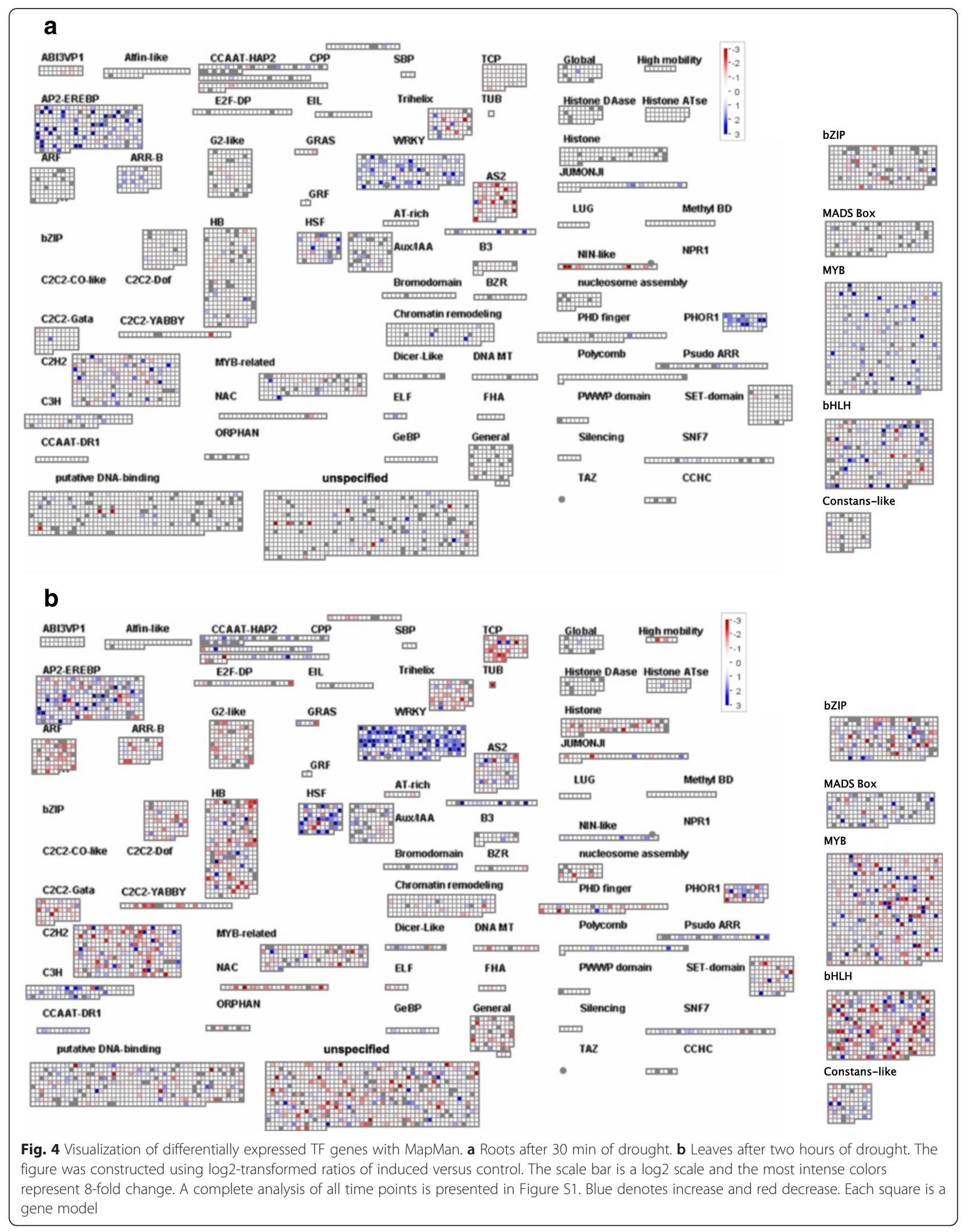




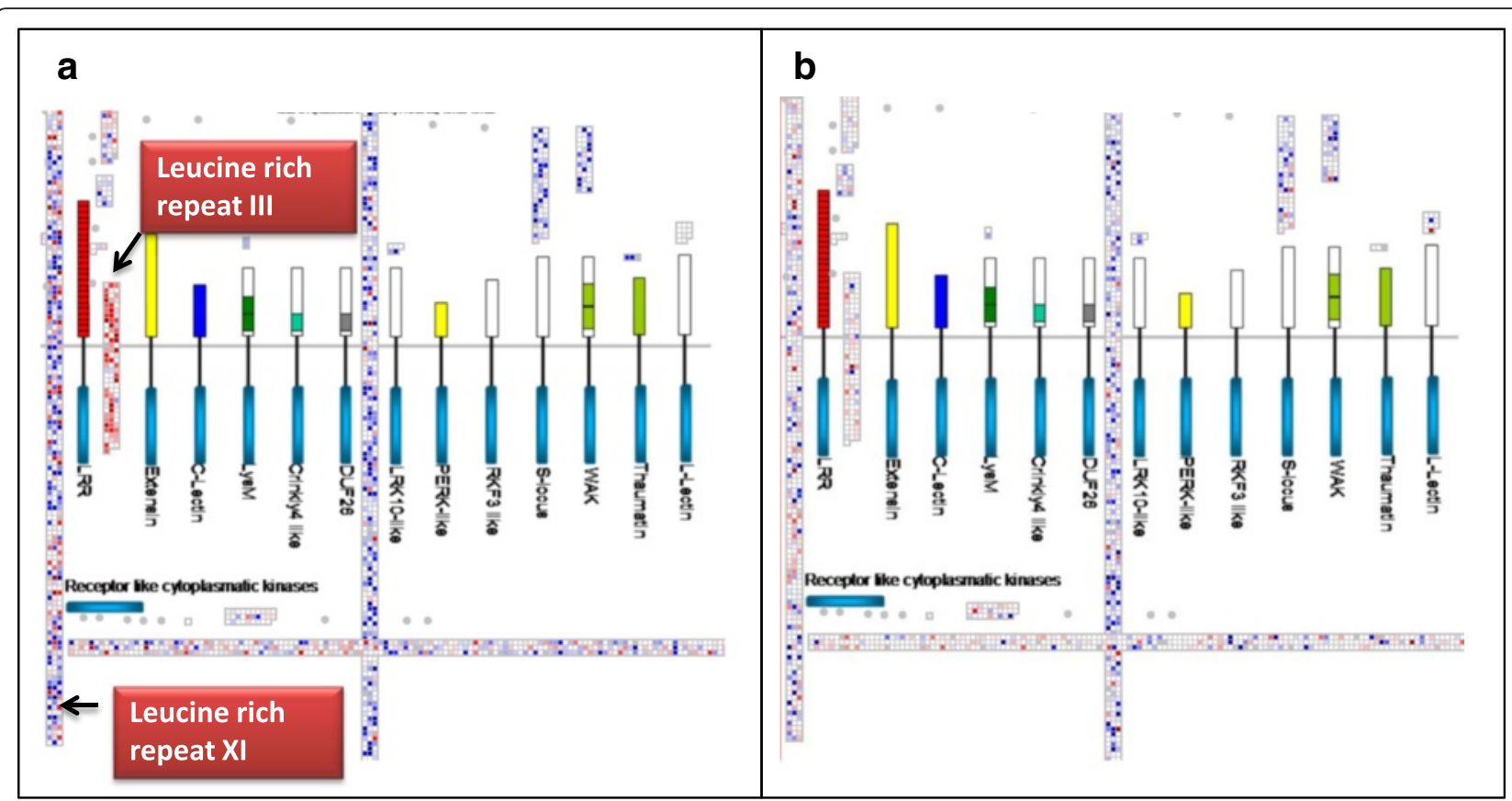

Fig. 5 Visualization of differentially expressed receptor-like kinase genes with MapMan. The receptor kinase bin 30.2 is illustrated. a Leaf and (b) Roots. Subfamilies III and XI are indicated. The figure was constructed using log2-transformed ratios of induced versus control. The most intense colors represent 8-fold change. Blue denotes increase and red decrease

the bHLH genes involved are different in legumes compared to the Brassicaceae.

FAMA, SPEECHLESS and MUTE regulate the last steps in the stomatal development signaling pathway (Fig. 6) but upstream components of the pathway are also known. In total 58 putative soybean orthologs of Arabidopsis stomatal development genes were identified and 24 of these showed differential expression (at least 5-fold change in mRNA level) (Additional file 16: Table S12). Strikingly, only one gene was upregulated and only two genes showed significant variations in mRNA levels in root. STOMAGEN is an intracellular signaling peptide that is a positive regulator of stomatal patterning and a striking reduction of over 40-fold in the mRNA level of the STOMAGENlike gene Glyma08g45890 was observed. These data reveal that orthologues of genes that regulate stomatal development are among the most strongly downregulated soybean genes during drought. This suggests that differentiation of stomata is reduced as a longterm response of soybean to drought. We validated the expression changes of fourteen genes from the oligo array using qRT-PCR (Additional file 17: Table S13). This included several stomatal development genes including GLYMA16g02020 (FAMA-like), GLYMA11g02520 (YODA MAP Kinase Kinase Kinaselike), and GLYMA19g35200 (Stomatal Density and Distribution-1).
To establish directly whether drought does indeed cause a reduction in stomatal density, soybean plants were grown in soil for four weeks and well-watered. Half of the plants were then subjected to drought stress by withholding water for three weeks. After this period, all plants were well watered for three weeks. Leaves were selected from the youngest trifoliates that had formed after the imposed drought period. This was determined by marking the youngest trifoliates before ending the drought. The drought stressed plants had an average stomatal density of $22.34 \%$ less than the well-watered plants and a reduction in leaf stomatal index of $17.56 \%$ (Table 2). This suggests that using stomatal development genes to reduce the amount of stomata may be a good strategy to improve drought tolerance.

\section{The promoter level}

Many approaches to the improvement of drought responses in soybean will involve the use of transgenes. The success or failure of these strategies may ultimately rest on the choice of promoter to regulate the expression of these transgenes. A data set was therefore constructed containing 1,000 bp of promoter region from the fifty most strongly induced genes at an early time-point $(1 \mathrm{~h}$ root and $2 \mathrm{~h}$ leaf) and a late time-point (5 h in both). These were analyzed by MEME [24] for the presence of conserved sequence motifs that might serve as components of synthetic drought-inducible promoters for the 


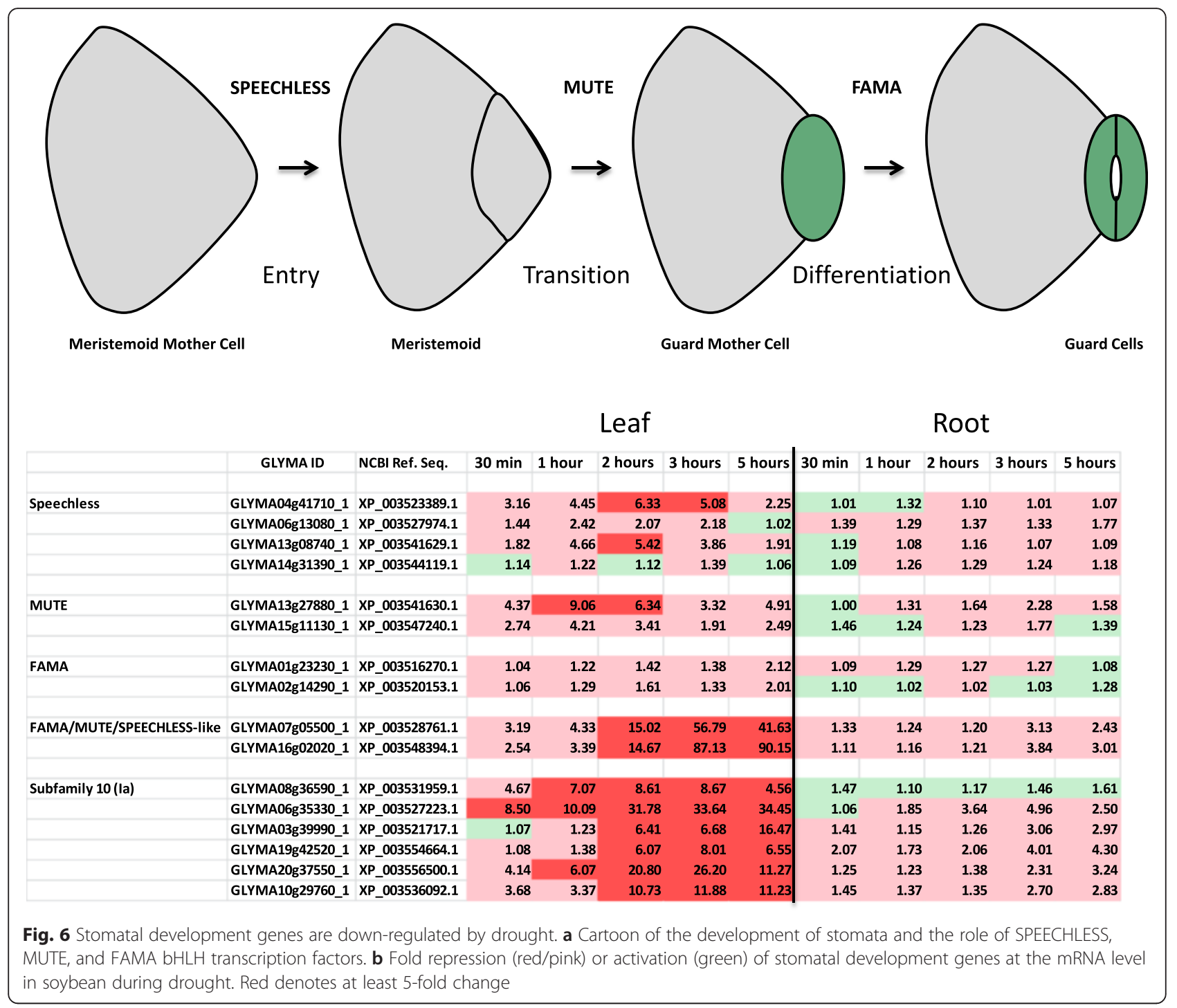

controlled expression of transgenes. As expected, in all four data sets there was a striking occurrence of the $G$ box-related ABRE sequence motif CACGT/CG (Fig. 8) with $42-60 \%$ of the promoters containing at least one ABRE-like sequence. Notably, the positions of the ABRE-like sequences are non-random with the majority occurring within $500 \mathrm{bp}$ of the predicted ATG. In leaf after two hours, $80 \%$ of ABRE-like sequences were within the 500 bp closest to the ATG (Fig. 8) and $70 \%$ were found in the first $280 \mathrm{bp}$. This is in contrast to most other sequences detected by MEME that showed a random distribution (data not shown). MEME analyses also identified the CRT/DRE motif CAC/TCGACC that was found in ten of the root early up-regulated promoters. In addition, the sequence motif GTGCnTGC/G (C/GCAnGCAC) was found in sixteen of the leaf late up-regulated promoters. This element would appear to be novel as it bears no significant similarity to any promoter element in the current list of binding sites in the AtcisDB database. It is unclear which transcription factors bind to the GTGCnTGC/G motif and it remains to be functionally characterized but it could prove to be a useful building block for synthetic drought-inducible promoters.

Our previous work in tobacco has shown that several WRKY gene promoters (notably NtWRKY69) direct water stress-inducible expression as shown by promoter:GFP or promoter:GUS analyses [16]. We therefore sought to validate and further characterize the inducibility of WRKY promoters from soybean because they could be good candidates for driving transgenes $[25,26]$. Promoter:GFP constructs of two promising WRKY genes, GmWRKY17 (GLYMA06g06530) and GmWRKY67 (GLYMA13g44730) were transformed into soybean roots via hairy-root 


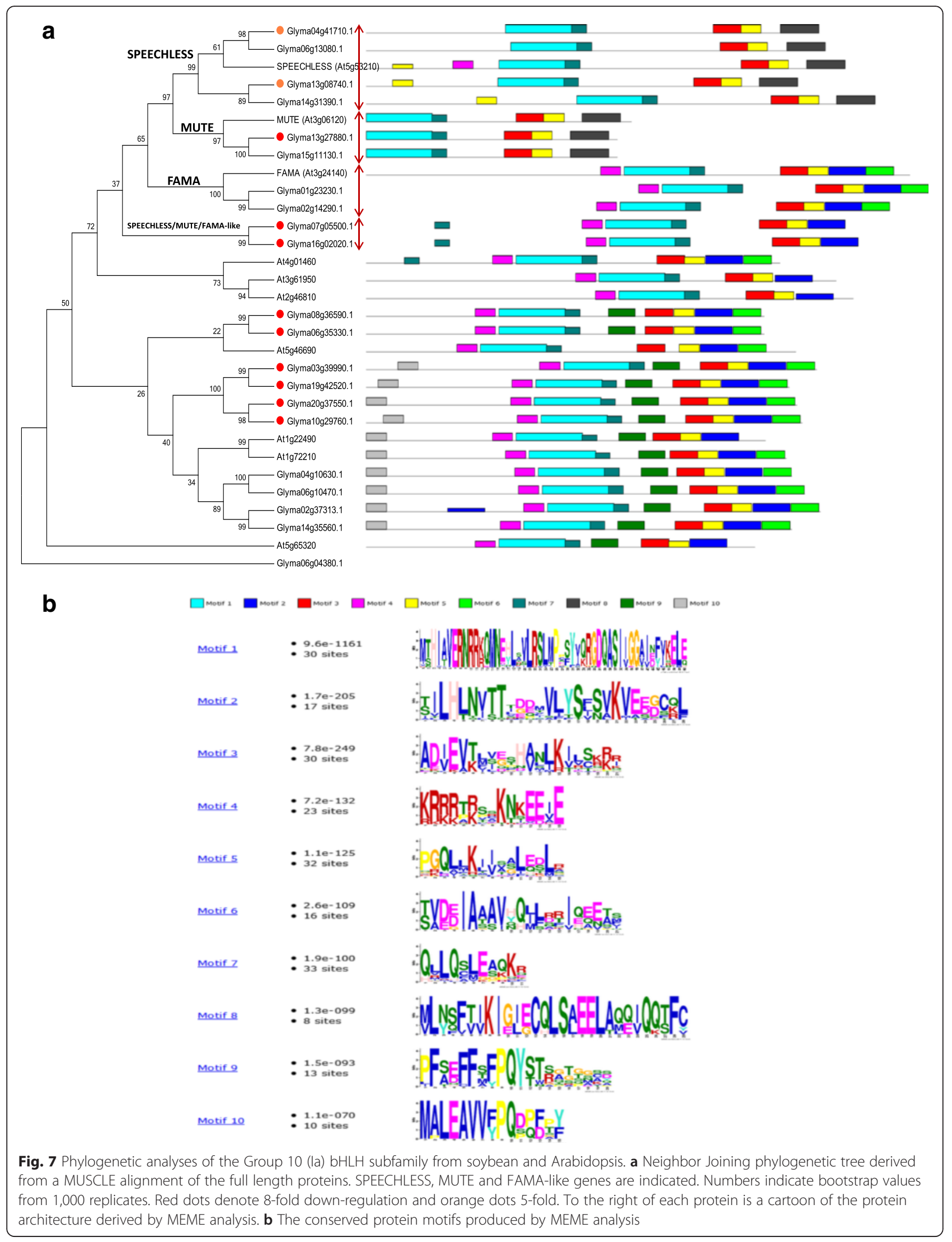


Table 2 Stomatal density and stomatal index in leaves formed before and after drought

\begin{tabular}{lcc}
\hline & $\begin{array}{c}\text { Average Stomatal Density } \\
\text { per unit surface area }\end{array}$ & $\begin{array}{l}\text { Leaf Stomatal Index } \\
{[\mathrm{s} /(\mathrm{s}+\mathrm{c})]}\end{array}$ \\
\hline Drought & 46.08 & 16.11 \\
Non-Drought & 59.33 & 19.55 \\
Percent Difference & -22.34 & -17.56 \\
P-Value & $3.387 \mathrm{E}-14$ & 0.0001 \\
\hline
\end{tabular}

transformation and transgenic roots were subjected to drought. GFP quantification confirmed drought inducibility and revealed that the promoter of GmWRKY17 directed 12.7-fold inducible expression and the GmWRKY67 promoter 4.8-fold (Fig. 9). Additionally, the GmWRKY17 promoter responded to ABA (Fig. 9) and both promoters were responsive to cold. This suggests that the promoters from GmWRKY17 and GmWRKY67 may prove useful for driving transgenes in projects aimed at improving drought responses. We have previously shown that the GmWRKY53 and GmWRKY112 promoters respond positively to exogenous application of salt and PEG [25, 26].

\section{Responses at the proteome level}

Surprisingly, drought responses at the protein level have not been investigated extensively in soybean [27] and the few reports do not look at the metabolite and mRNA levels in the same samples. We therefore performed a proteomics study using the same set of root samples used for transcriptomics and metabolomics. A gel-free shotgun proteomics approach was employed that utilized Multi-Dimensional Protein Identification Technology (MuDPIT). Out of 2,471 identified proteins, 122 proteins were found to have significant differences in level after three hours or five hours compared to control roots (Additional file 18: Table S14). Strikingly, more proteins showed a reduction in abundance than an increase, suggesting that protein degradation/turnover is a characteristic of the drought response. Recently, the proteome of soybean roots subjected to short-term drought stress was studied [28]. Although only 28 proteins were identified that showed variations in abundance 21 of these showed a similar reduction in level to our observations.

Several trends could be observed (Additional file 18: Table S14). Firstly, metabolism-related proteins that are involved in energy production are reduced in abundance. This includes proteins involved in glycolysis, the TCA cycle, and oxidative phosphorylation. This correlates with a reduction in many photosynthesis-related genes at the mRNA level and shows that drought adversely affects photosynthesis and energy production and consequently reduces plant growth. Secondly, some signaling proteins were up-regulated at the protein level. This included a MAP kinase, casein kinase, receptor kinase, inositol 1,4,5trisphosphate 5-phosphatase, and calmodulin-binding protein. Some are similar to stress-inducible genes/proteins from other plants (Table 1).

\section{Discussion}

New strategies for improving soybean drought responses We have analyzed soybean plants using systems biology approaches during water stress. Our extensive data sets revealed a number of novel biological insights and also potential transgenes, drought inducible promoters, and metabolic pathways to target in projects aimed at improving drought tolerance (Table 1). Figure 10 shows an overview of potential strategies to use this toolbox to produce soybean plants with improved drought tolerance. This includes overexpression, knockdown, knockout, and altered tissue-specific expression using specific regulatory genes, stomatal development genes, hormone biosynthesis and response genes, genes involved in secondary metabolism, and other downstream droughtinducible genes. Many of these genes could also form the basis of non-transgenic approaches using marker assisted breeding. In addition, the large increase in coumestrol observed in roots could make it a biomarker for drought because coumestrol levels can be easily measured and the increase in levels is both early and massive.

The first two parts of any strategy aimed at improving drought tolerance by transgenic means needs to answer two questions: What are we going to express? (the choice of transgene) and how are we going to express it? (the choice of promoter/expression cassette). It is likely that many previous projects have failed not because of a poor choice of transgene but rather due to the choice of an inappropriate promoter. Ectopic overexpression using promoters such as the CaMV 35S promoter have often been previously used and this uncontrolled expression may lead to improved drought tolerance but in many cases may also lead to reductions in yield due to constitutive activation of abiotic stress responses. One possible solution is the use of drought-inducible promoters and/ or tissue specific promoters. Our toolbox includes several native promoters than direct drought-inducible expression and our previous work has identified other similar promoters from tobacco that may also function well in soybean, notably NtWRKY69, NtUPLL2, and $N t G o l S$ [16]. Our MEME analyses have shown that the ABRE, DRE and novel GTGC elements are found in the promoters of the most strongly drought-induced genes (Fig. 8). These three elements can form the building blocks for improved synthetic drought-inducible promoters that can be engineered to be paired with 


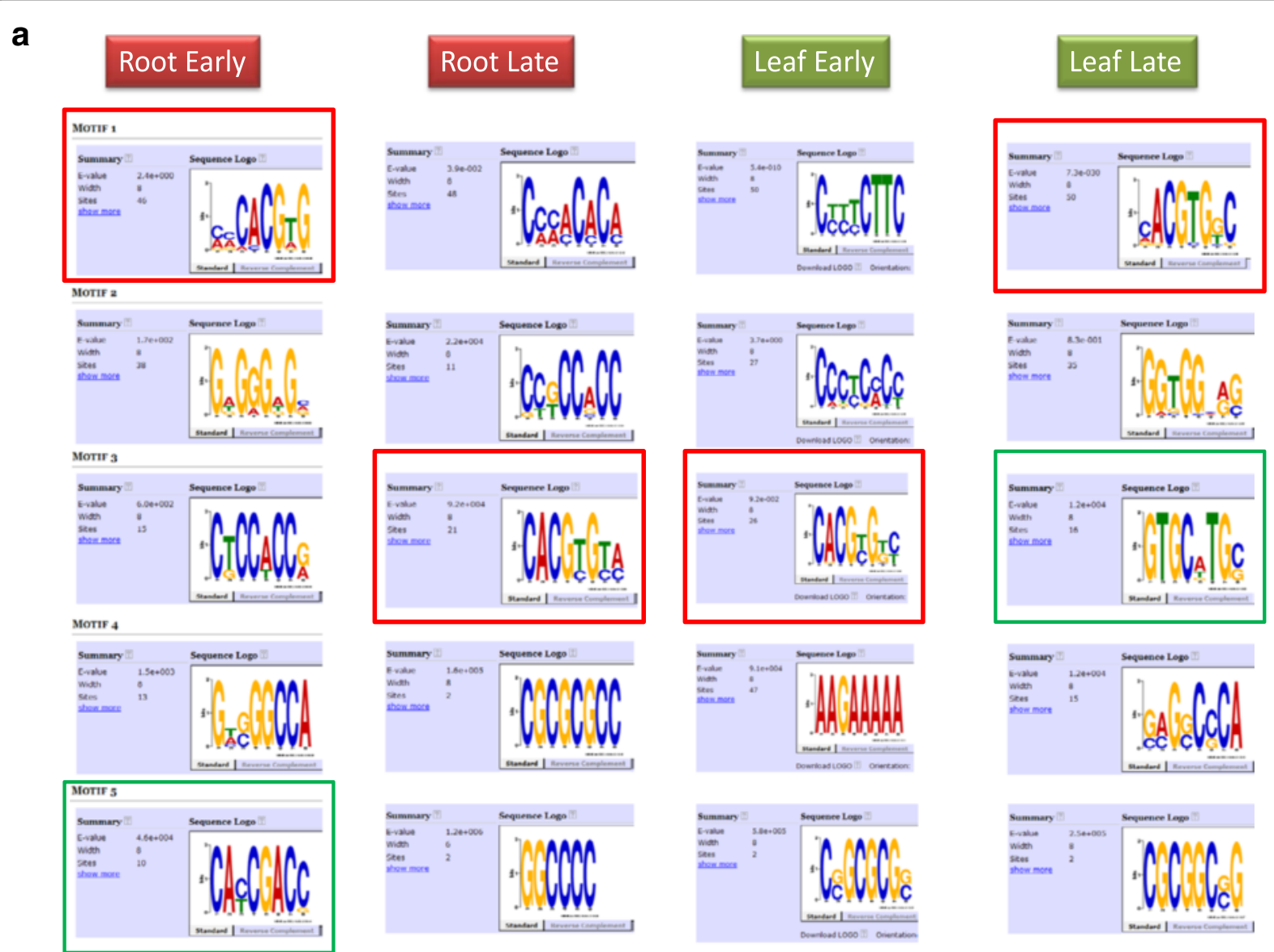

b

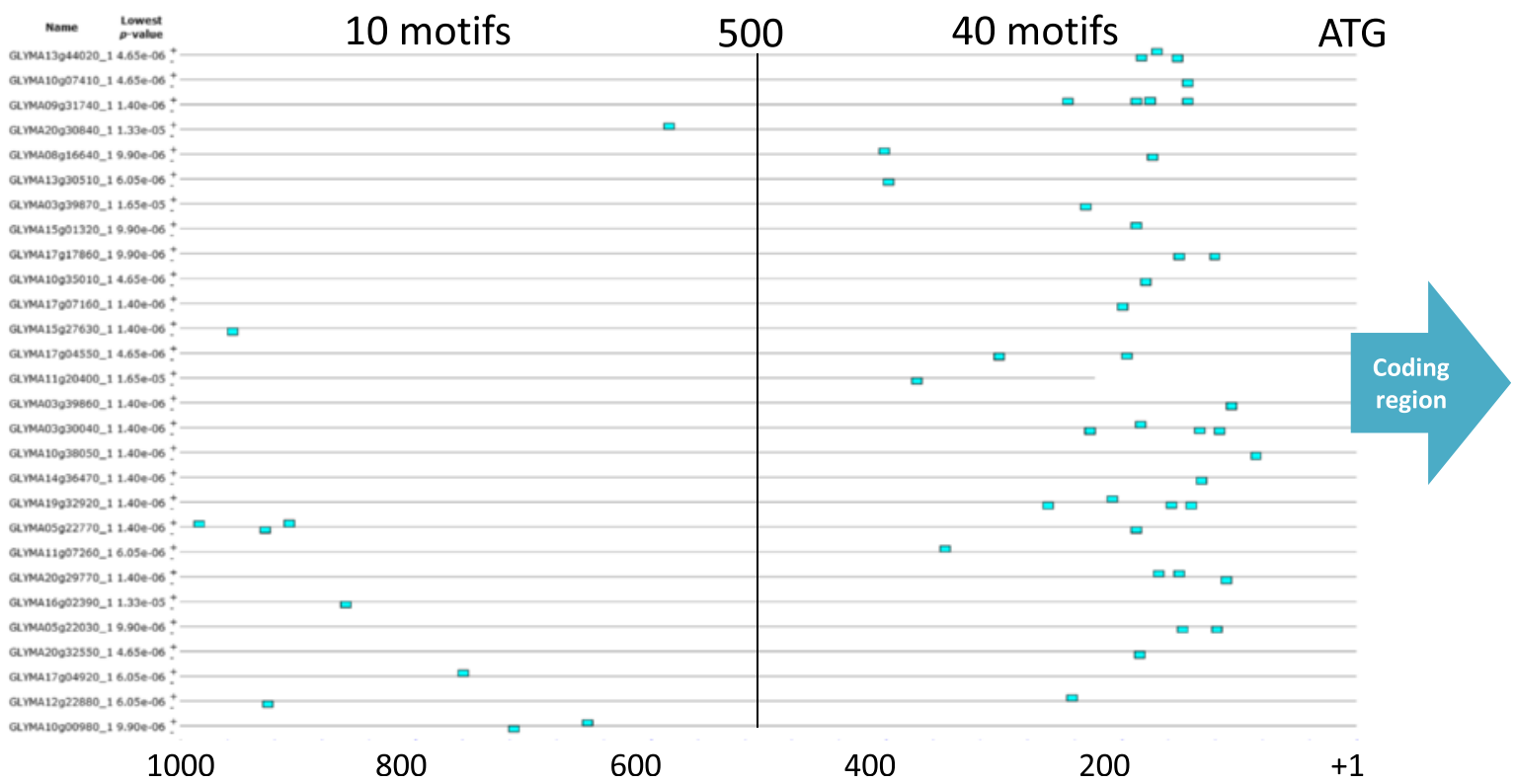

Fig. 8 Non-random clustering of ABRE-like sequences in the $500 \mathrm{bp}$ upstream of the ATG in the promoters of the fifty most strongly upregulated genes at two time points from leaf and root. a The consensus sequences of the ABRE-like sequences derived from MEME for the four timepoints are shown, together with the number of sites and percentage of genes containing at least one site. $\mathbf{b}$ Cartoon representation of the ABRE-like sequences in the promoter regions of the genes from the leaf two hour time point. Blue rectangles denote ABRE-like sequences. Green rectangles denote non-ABRE sequences 


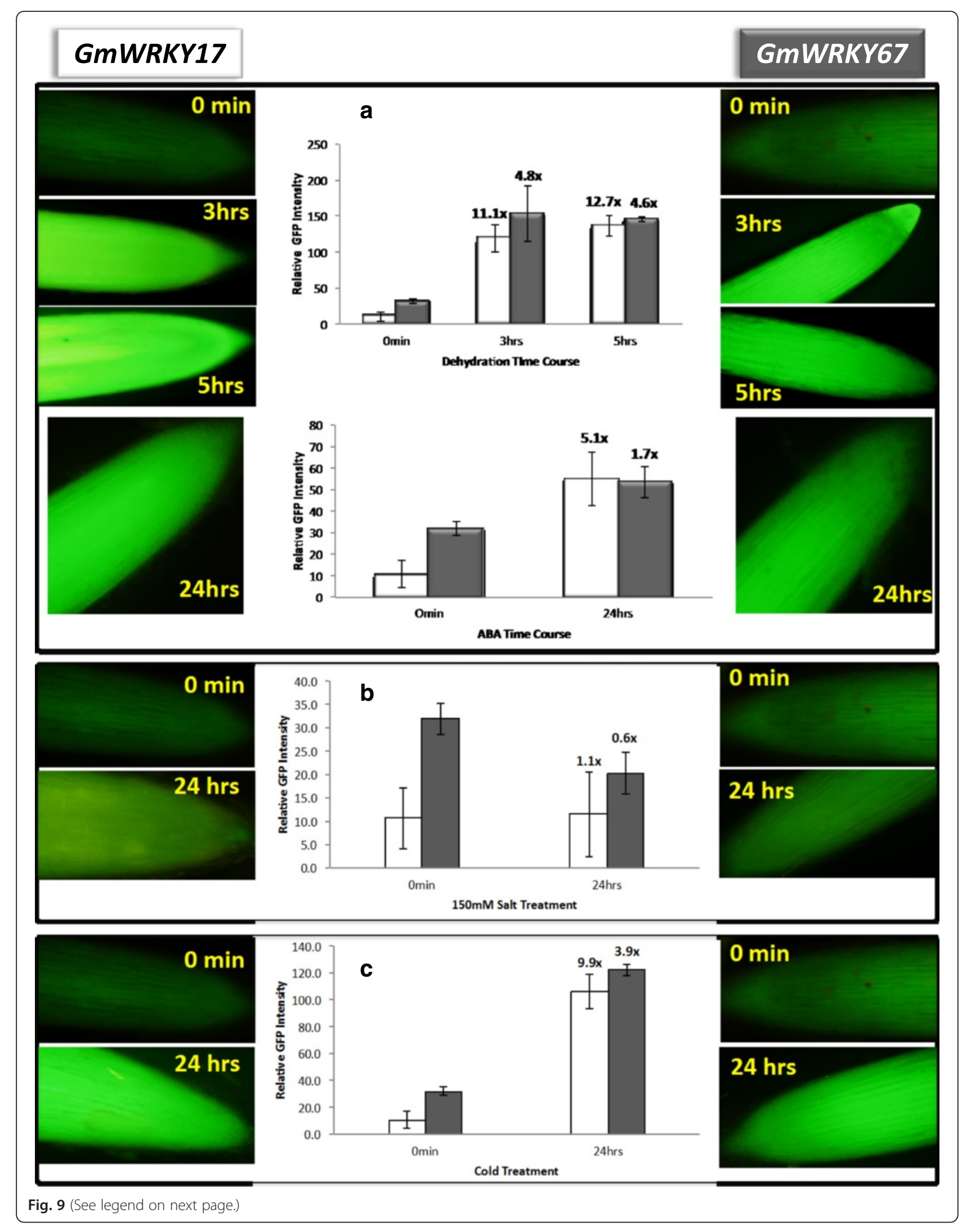


(See figure on previous page.)

Fig. 9 Validation of promoter activity of GmWRKY17 and GmWRKY67 in soybean hairy-roots during dehydration and $20 \mu M$ ABA treatment. Validation of promoter activity via visualization and quantification of a promoter:GFP construct of GmWRKY17 and GmWRKY67 in soybean hairyroots during (a) dehydration (b) $20 \mu \mathrm{M}$ ABA treatment and (c) cold. The time points in hours are shown. The graph shows mean \pm standard error for 9 independent plants for each time point. The fold inducibilities are indicated

transgenes to produce improved expression cassettes for each transgene and each strategy.

However, the difficulties in improving drought tolerance in plants should not be underestimated because drought tolerance is a complex quantitative and multigenic trait with a significant environmental component $[2,3]$. The genetic control of traits associated with tolerance to drought often shows low heritability and as a result water stress responses from hydroponics, growth chambers, greenhouses, and field conditions often vary. For this reason the only real judge of success is field performance. Over the years, one of the major problems with transgenic plant lines is that they are ill-defined, neglect physiology and that the phenotypes are unspecific in their definitions. However, a more exact characterization and comparison of transgenic lines can be provided by new advances in phenomics. High-throughput phenotyping will greatly facilitate the characterization of transgenic lines, especially under field conditions, and this precision phenotyping approach should be a major part of strategies to improve drought tolerance (Fig. 10).

\section{Coumestrol and a possible drought tolerance mechanism}

One of the greatest challenges facing agriculture is the availability of water. Any new mechanism that promises to lead to new biotechnological approaches to reduce

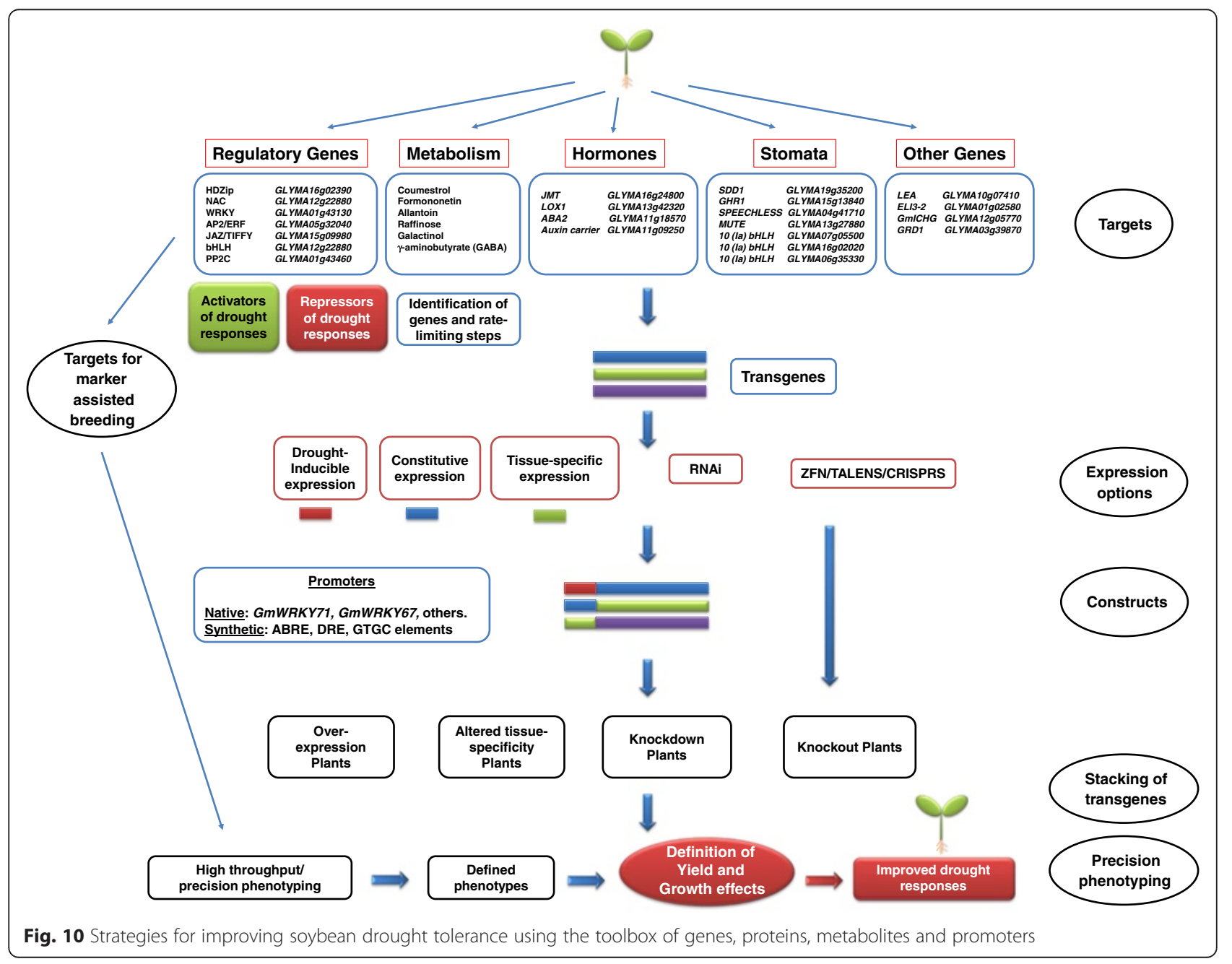


the amount of water required to irrigate crops is therefore noteworthy. Our data suggest we may have found just such a mechanism linking drought, coumestrol, and mycorrhiza. Isoflavonoids, such as coumestrol, may function as signals in mycorrhizal interactions with plant roots [29]. Coumestrol accumulates to significant levels in mycorrhizal soybean roots [30] and stimulates growth of hyphae of the arbuscular mycorrhizal fungus Gigaspora margarita [31]. Coumestrol has also been shown to double the degree of mycorrhizal colonization when added to the soil of mycorrhizal soybean plants [32]. Importantly, mycorrhizal symbiosis can enhance plant tolerance to drought stress through altering plant physiology and gene expression [33]. Under drought stress, mycorrhiza affects water movement into the plant, influencing plant hydration and physiological processes [34]. As a result, mycorrhizal plants can have higher water use efficiency and enhanced growth when irrigation is restored [33].

Our work has provided new information, namely that drought stressed soybean plants very rapidly accumulate coumestrol in the roots. We therefore hypothesize that drought induces a large increase in coumestrol in the roots of legumes. This increase is an inducible mechanism to improve water use efficiency by promoting the growth of mycorrhizal fungi and thereby increasing the amount of water that the plant can reach and/or retain. Coumestrol therefore represents a new target to improve drought tolerance in legumes. However, the enzymes responsible for coumestrol biosynthesis between daidzein and coumestrol are unknown and what little is known comes from tracer studies from the 1970s [35, 36]. Identification of these enzymes is now a priority as they will be required for successful manipulation of coumestrol levels in planta.

Unanswered questions include the effect of coumestrol on mycorrhiza. We do not know whether increased mycorrhizal growth is limited to pre-existing mycorrhizal interactions or whether coumestrol promotes new interactions or both. It is also unclear whether the increase in coumestrol levels is the result of de novo synthesis or the release of free coumestrol from pools in the vacuole of stored conjugated forms. It has been proposed that an isoflavone conjugate-hydrolyzing $\beta$ glucosidase ( $\mathrm{GmICHG}$ ) releases these conjugated isoflavones from their latent forms in the vacuole to be excreted from the roots to promote plant-microbe interactions [37]. Interestingly, our transcriptome analyses reveal that GmICHG (GLYMA12g05770) is among the 170 most highly expressed genes in soybean roots.

\section{Drought induced changes in the stomatal development program}

It is clear from our data that stomata are a major target for both short and long term responses to drought. Stomatal closure is one of the most rapid responses to drought starting within $30 \mathrm{~min}$ and being essentially complete within two hours. A rapid response with similar kinetics is also seen at the mRNA level with the down-regulation of the GHR1 gene that mediates $\mathrm{ABA}$ and hydrogen peroxide-regulated stomatal movement under drought stress. Stomata are also the target of long-term responses to drought stress with fewer stomata on leaves formed after drought (Table 2). Three orthologues of stomatal development genes are among the 29 most highly down-regulated genes in soybean leaves after three hours of drought. One of these genes encodes STOMAGEN an intracellular signaling peptide that is a positive regulator of stomatal patterning. The other two are FAMA/MUTE/SPEECHLESS-like bHLH transcription factors. This agrees with previous research in Arabidopsis [38] and poplar [39]. The situation in soybean is more complex than Arabidopsis even taking into account the ploidy. In several instances, not all paralogs show a similar expression pattern. Also in soybean, the FAMA orthologues are not differentially regulated. Instead, two other more distant members of the clade that are related to all three bHLH genes are very strongly downregulated. The situation in soybean becomes even more complex with the inclusion of six other subfamily 10 (Ia) bHLH genes that form a broader clade with the FAMA/MUTE/SPEECHLESS-like genes. Six of these subfamily 10 (Ia) bHLH genes show strong downregulation in leaf tissue. One strategy to improving soybean drought tolerance may be to target stomatal density via the manipulation of these genes.

\section{Conclusions}

We have identified targets for the biotechnological improvement of drought responses in soybean. Together with the promoters and promoter elements identified in this study, they form a toolbox of components for strategies to improve drought tolerance. Figure 10 shows how projects using this toolbox could generate improved soybean plants. Precision phenotyping, especially field phenotyping, is an important later component to help determine the exact phenotype of generated plants and the effects of transgene expression on yield, growth, and drought tolerance.

\section{Methods}

\section{Plant materials}

We have recently published an accompanying publication providing a detailed protocol of how we performed the experiments in this report [40]. Briefly, soybean Williams-82 seeds were grown in hydroponics using $0.5 \times$ Hoagland solution, pH 5.8 in a growth chamber with a $16 \mathrm{~h} / 8 \mathrm{~h}$ day/ night cycle at $25{ }^{\circ} \mathrm{C}$ and $50 \%$ relative humidity. After 30 days, plants were subjected to water stress by removing 
them without touching the plants. Leaves and roots were harvested by flash freezing in liquid nitrogen. Nine plants were utilized for each time-point (three replicates per time-point and three plants per replicate). These samples were utilized for all transcriptomics, proteomics and metabolomics experiments.

\section{Physiological measurements}

For TWC (\%), three punches of the same diameter were taken and weighed to determine the fresh weight (FW). Samples were lyophilized and dry weight determined (DW). TWC (\%) was calculated by (FW-DW)/FW $\times 100$. For osmotic potential, tissues were harvested and frozen at $-80{ }^{\circ} \mathrm{C}$ in $1.5 \mathrm{ml}$ eppendorf tubes containing a separator and centrifuged for $10 \mathrm{~min}$ at $5000 \mathrm{rpm} .10 \mu \mathrm{l}$ of liquid was used for measuring osmolality $(\mathrm{mMol} / \mathrm{kg})$ using an osmometer. Stomatal conductance $\left(\mathrm{mMol} / \mathrm{m}^{2} \mathrm{~s}\right)$ was measured with a steady state diffusion porometer. Phytohormone analysis was performed at the Proteomics and Mass Spectrometry Facility, Danforth Plant Science Center, St Louis, MO. Stomatal density was determined using the impression method. The harvested leaves were covered with clear nail varnish between two auxiliary veins from the central vein to the leaf edge on the abaxial side. A photomicroscope system was used for counting of stomata (s) and epidermal cells (c). Stomatal density was determined as both a function of leaf surface area and as leaf stomatal index $[\mathrm{s} /(\mathrm{s}+\mathrm{c})] \times 100]$ [41]. 80 clear varnish stomatal imprints were collected from 26 different leaves which were harvested from 14 separate drought treated plants. 102 imprints were taken from 37 leaves which were harvested from 17 non-drought plants.

\section{Transcriptomics analyses}

RNA was isolated using QIAGEN@ RNeasy-MIDI. $10 \mu \mathrm{g}$ total RNA from each sample was used for micro-array analysis. A custom made $12 \times$ plex array was designed by Roche NimbleGen, Inc. containing multiple $60 \mathrm{mer}$ oligomers to all genes from the GLYMAv1.0 release of the soybean genome. Oligoarray experiments were performed at MOgene, LLC (St Louis, MO). Data analysis was performed using ArrayStar v4. Differential regulation was calculated using $90 \%$ confidence (FDR Benjamini Hochberg) and 8-fold change. For gene enrichment analysis, agriGO [42] was employed and enriched GO terms were obtained using Singular Enrichment Analysis [43]. Pathway visualization was performed by MapMan. The transcriptome data set is available in the Gene Expression Omnibus under the accession number GSE49537.

\section{Motif analyses}

Conserved motifs in promoters were found using MEME (http://meme-suite.org/tools/meme) [24] with motif widths set at eight nucleotides as described in Tripathi et al. [44].

\section{Proteomics analyses}

Roots tissues were processed at Bio-Proximity, LLC as described $[45,46]$. MGF data files were searched using X!Hunter against the latest library on the GPM [47] and also searched using X!Tandem [48, 49] using both the native and k-score [50] scoring algorithms and by OMSSA [51]. Proteins were required to have 2 or more unique peptides with E-value scores of 0.01 or less. The proteomics data was used for identification of differentially regulated proteins with an FDR correction of $5 \%$.

\section{Metabolomics analyses}

Metabolomics analyses were performed at Metabolon, Inc. (North Carolina). The global unbiased metabolic profiling platform was based on a combination of three independent platforms: UHLC/MS/MS2 optimized for basic species, UHLC/MS/MS2 optimized for acidic species, and GC/MS. This platform has been described in detail [52]. Three replicates were used per time-point and rigorous statistical analyses were performed. Following $\log$ transformation and imputation with minimum observed values for each compound, Welch's twosample t-test was used to identify biochemicals that differed significantly between different time points and in different tissues. The statistical significance threshold was set at $p \leq 0.05$. An estimate of the false discovery rate (q-value) was also calculated (Additional file 1: Table S1) to take into account the multiple comparisons in the study and a low q-value $(\mathrm{q}<0.10)$ showed an indication of high confidence in the major results.

\section{Soybean hairy-root transformation and GFP Quantification}

Promoter sequences ( $1 \mathrm{~kb}$ upstream from the ATG) including the 5'UTRs were obtained from phytozome [53]. The promoters were cloned into pFLEV [54] and transformed into LBA4404 agrobacterium cells by electroporation.

Soybean hairy-root transformation was performed as described [55]. After 3-4 weeks, the plants were transferred to hydroponics and dehydration was performed as described above. The roots were observed under an OLYMPUS AX70 upright compound microscope. Eleven to fourteen transformed hairy-roots were analyzed per construct. GFP quantification was performed with Image $J$ [56].

For measuring $\mathrm{ABA}$ inducibility, transformed roots were placed in $20 \mu \mathrm{M}$ ABA for $24 \mathrm{~h}$. For cold treatment, plants were transferred to boxes with ice. For salt treatment, plants were placed in $150 \mathrm{mM} \mathrm{NaCl}$ for $24 \mathrm{~h}$. 


\section{Availability of data and materials}

We have made the soybean oligo array data available at the Gene Expression Omnibus online repository as GEO accession GSE49537.

\section{Additional files}

Additional file 1: Table S1. Heat maps and box plots of all detectable metabolites of known identity. (XLSX 1476 kb)

Additional file 2: Figure S1. Up regulation of raffinose and galactinol synthase genes correlates with increases in galactinol and raffinose. (PDF $236 \mathrm{~kb}$ )

Additional file 3: Figure S2. Metabolite analysis of the ammonia detoxification processes (PDF $184 \mathrm{~kb}$ )

Additional file 4: Table S2. Complete list of differentially expressed genes at the mRNA level at the different time points in leaves and roots (XLSX $1382 \mathrm{~kb}$ )

Additional file 5: Figure S3. Gene ontology analysis. (PDF 315 kb) Additional file 6: Table S3. Significant GO terms root $1 \mathrm{~h}$. (XLSX $12 \mathrm{~kb}$ ) Additional file 7: Table S4. Significant GO terms root $30 \mathrm{~min}$. Molecular Function and Biological Process category enriched GO terms. (XLSX $14 \mathrm{~kb}$ )

Additional file 8: Table S5. Significant GO terms root $5 \mathrm{~h}$. (XLSX $18 \mathrm{~kb}$ ) Additional file 9: Table S6. Significant GO terms leaf 2 h. (XLSX 14 kb) Additional file 10: Table S7. Significant GO terms leaf 5 h. (XLSX 17 kb) Additional file 11: Table S8. List of differentially expressed TF genes after $30 \mathrm{~min}$ in roots (XLSX $12 \mathrm{~kb}$ )

Additional file 12: Table S9. List of differentially expressed TF genes after $2 \mathrm{~h}$ in leaves (XLSX $23 \mathrm{~kb}$ )

Additional file 13: Table S10. Differentially expressed calcium signaling-associated genes from MapMan (XLSX 16 kb)

Additional file 14: Table S11. bHLH genes in soybean. (XLSX 18 kb) Additional file 15: Figure S4. Phylogenetic analyses of the $b H L H$ transcription factor family from soybean. (PDF $71 \mathrm{~kb}$ )

Additional file 16: Table S12. Soybean orthologs of Arabidopsis stomatal development genes. (DOC $34 \mathrm{~kb}$ )

Additional file 17: Table S13. qRT-PCR verification of expression patterns of 14 genes from the oligo array analysis. (PDF $1550 \mathrm{~kb}$ )

Additional file 18: Table S14. Differentially accumulated proteins during dehydration in soybean roots. (XLSX $23 \mathrm{~kb}$ )

\section{Competing interests}

The authors declare that they have no competing interests.

\section{Authors' contributions}

All authors conceived the experiments. PT, RCR, and PJR wrote the paper. All authors have read and approved the manuscript.

\section{Acknowledgements}

We thank P. G. Naveen Kumar for help with the stomata experiments and Ying-Sheng Huang for help with the qRT-PCR. The authors thank Marie Turner, Kathie Mathiason and Stephanie Hansen for help in experimental set up and Deena Rushton for her help with several tables. We also thank Nalini Desai and John Ryals at Metabolon Inc. and Brian Balgley at Bioproximity LLC. This project was supported in part by National Research Initiative grants 2008-35100-04519 and 2008-35100-05969 from the USDA National Institute of Food and Agriculture.

\section{Author details}

'Department of Biology and Microbiology, South Dakota State University, Brookings SD57007, USA. ${ }^{2}$ Texas A\&M AgriLife Research and Extension Center, Dallas, TX 75252, USA. ${ }^{3}$ School of Life Sciences, University of Nevada, Las Vegas 89154, USA. ${ }^{4}$ INRA, UMR 1347 Agroécologie, 17 rue Sully, BP
86510, 21065 Dijon, CEDEX, France. ${ }^{5}$ Department of Biological Sciences, University of North Texas, Denton, TX 76203, USA. ${ }^{6}$ Current address, Molecular and Computational Biology, Dana \& David Dornsife College of Letters, Arts and Sciences, University of Southern California, Los Angeles, CA 90089, USA. ${ }^{7}$ Current address: Texas A\&M AgriLife Research and Extension Center, Dallas, TX 75252, USA. ${ }^{8}$ Current address, 22nd Century Group Inc., 9530 Main Street Clarence, New York 14031, USA.

Received: 18 September 2015 Accepted: 26 January 2016

Published online: 09 February 2016

\section{References}

1. Araus JL, Slafer GA, Reynolds MP, Royo C. Plant Breeding and Drought in C3 Cereals: What Should We Breed For? Ann Bot. 2002;89:925-40.

2. Langridge P, Fleury D. Making the most of 'omics' for crop breeding. Trends Biotechnol. 2011;29:33-40.

3. Mir RR, Zaman-Allah M, Sreenivasulu N, Trethowan R, Varshney RK. Integrated genomics, physiology and breeding approaches for improving drought tolerance in crops. TAG Theor Appl Genet. 2012;125:625-45.

4. Tripathi P, Rabara RC, Rushton PJ. A systems biology perspective on the role of WRKY transcription factors in drought responses in plants. Planta. 2014; 239:255-66.

5. Guimaraes-Dias F, Neves-Borges AC, Viana AA, Mesquita RO, Romano E, de Fatima Grossi-de-Sa M, et al. Expression analysis in response to drought stress in soybean: Shedding light on the regulation of metabolic pathway genes. Genet Mol Biol. 2012;35:222-32.

6. Neves-Borges AC, Guimaraes-Dias F, Cruz F, Mesquita RO, Nepomuceno AL,

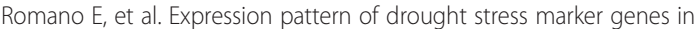
soybean roots under two water deficit systems. Genet Mol Biol. 2012;35: 212-21.

7. Soares-Cavalcanti NM, Belarmino LC, Kido EA, Wanderley-Nogueira AC, Bezerra-Neto JP, Cavalcanti-Lira R, et al. In silico identification of known osmotic stress responsive genes from Arabidopsis in soybean and Medicago. Genet Mol Biol. 2012;35:315-21.

8. Chen LM, Zhou XA, Li WB, Chang W, Zhou R, Wang C, et al. Genome-wide transcriptional analysis of two soybean genotypes under dehydration and rehydration conditions. BMC Genomics. 2013;14:687.

9. Le DT, Nishiyama R, Watanabe Y, Tanaka M, Seki M, Ham LH, et al. Differential Gene Expression in Soybean Leaf Tissues at Late Developmental Stages under Drought Stress Revealed by Genome-Wide Transcriptome Analysis. PLoS One. 2012;7, e49522.

10. Shin JH, Vaughn JN, Abdel-Haleem H, Chavarro C, Abernathy B, Kim KD, et al. Transcriptomic changes due to water deficit define a general soybean response and accession-specific pathways for drought avoidance. BMC Plant Biol. 2015;15:26.

11. Prince, S.J., Murphy, M., Mutava, R.N., Zhang, Z., Nguyen, N., Kim, Y.H., Pathan, S.M., Shannon, G.J., Valliyodan, B. and Nguyen, H.T (2015). Evaluation of high yielding soybean germplasm under water limitation. J. Int. Plant Biol. doi: 10.1111/jipb.12378. [Epub ahead of print].

12. Harb A, Krishnan A, Ambavaram MM, Pereira A. Molecular and physiological analysis of drought stress in Arabidopsis reveals early responses leading to acclimation in plant growth. Plant Physiol. 2010;154:1254-71.

13. Moore JP, Le NT, Brandt WF, Driouich A, Farrant JM. Towards a systemsbased understanding of plant desiccation tolerance. Trends Plant Sci. 2009; 14:110-7.

14. Seki M, Umezawa T, Urano K, Shinozaki K. Regulatory metabolic networks in drought stress responses. Curr Opin Plant Biol. 2007;10:296-302.

15. Oliver MJ, Guo L, Alexander DC, Ryals JA, Wone BW, Cushman JC. A sister group contrast using untargeted global metabolomic analysis delineates the biochemical regulation underlying desiccation tolerance in Sporobolus stapfianus. Plant Cell. 2011;23:1231-48.

16. Rabara RC, Tripathi P, Reese RN, Rushton DL, Alexander D, Timko MP, et al. Tobacco Drought Stress Responses Reveal New Targets for Solanaceae Crop Improvement. BMC Genomics. 2015;16:484.

17. Watanabe S, Matsumoto M, Hakomori Y, Takagi H, Shimada H, Sakamoto A. The purine metabolite allantoin enhances abiotic stress tolerance through synergistic activation of abscisic acid metabolism. Plant Cell Environ. 2014; 37:1022-36.

18. Lee HI, Lee JH, Park KH, Sangurdekar D, Chang WS. Effect of soybean coumestrol on Bradyrhizobium japonicum nodulation ability, biofilm formation, and transcriptional profile. Appl Environ Microbiol. 2012;78:2896-903. 
19. Samanta A, Das G, Das SK. Roles of Flavonoids in Plants. Int J Pharm Sci Tech. 2011:6:12-35.

20. Osakabe Y, Arinaga N, Umezawa T, Katsura S, Nagamachi K, Tanaka H, et al. Osmotic stress responses and plant growth controlled by potassium transporters in Arabidopsis. Plant Cell. 2013;25:609-24.

21. Hua D, Wang $C$, He J, Liao H, Duan $Y$, Zhu Z, et al. A plasma membrane receptor kinase, GHR1, mediates abscisic acid- and hydrogen peroxideregulated stomatal movement in Arabidopsis. Plant Cell. 2012;24:2546-61.

22. Ohashi-lto K, Bergmann DC. Arabidopsis FAMA controls the final proliferation/differentiation switch during stomatal development. Plant Cell. 2006;18:2493-505.

23. Shultz JL, Kurunam D, Shopinski K, labal MJ, Kazi S, Zobrist K, et al. The Soybean Genome Database (SoyGD): a browser for display of duplicated, polyploid, regions and sequence tagged sites on the integrated physical and genetic maps of Glycine max. Nucleic Acids Res. 2006;34:D758-65.

24. Bailey TL, Boden M, Buske FA, Frith M, Grant CE, Clementi L, et al. MEME SUITE: tools for motif discovery and searching. Nucleic Acids Res. 2009;37: W202-8.

25. Rabara RC, Tripathi P, Lin J, Rushton PJ. Dehydration-induced WRKY genes from tobacco and soybean respond to jasmonic acid treatments in BY-2 cell culture. Biochem Biophys Res Commun. 2013;431:409-14.

26. Tripathi P, Rabara RC, Lin J, Rushton PJ. GmWRKY53, a water- and saltinducible soybean gene for rapid dissection of regulatory elements in BY-2 cell culture. Plant Signal Behav. 2013;8.

27. Hossain Z, Komatsu S. Potentiality of soybean proteomics in untying the mechanism of flood and drought stress tolerance. Proteomes. 2014;2:107-27.

28. Alam I, Sharmin S, Kim K-H, Yang J, Choi M, Lee B-H. Proteome analysis of soybean roots subjected to short-term drought stress. Plant Soil. 2010;333: 491-505.

29. Harrison MJ, Dixon RA. Isoflavonoid accumulation and expression of defense gene transcripts during the establishment of vesicular arbuscular mycorrhizal associations in roots of Medicago truncatula. Mol Plant Microbe Interact. 1993;6.

30. Morandi D, Bailey JA, Gianinazzi-Pearson V. Isoflavonoid accumulation in soybean roots infected with vesicular-arbuscular mycorrhizal fungi. Physiol Plant Pathology. 1984;24:357-64.

31. Morandi D, Branzanti B, Gianinazzi-Pearson V. Effect of some plant flavonoids on in vifro behaviour of an arbuscular mycorrhizal fungus. Agronomie. 1992;12:811-6.

32. Xie ZP, Staehelin C, Vierheilig H, Wiemken A, Jabbouri S, Broughton WJ, et al. Rhizobial Nodulation Factors Stimulate Mycorrhizal Colonization of Nodulating and Nonnodulating Soybeans. Plant Physiol. 1995;108:1519-25.

33. Miransari M. Contribution of arbuscular mycorrhizal symbiosis to plant growth under different types of soil stress. Plant Biol (Stuttg). 2010;12:563-9.

34. Augé RM. Water relations, drought and vesicular-arbuscular mycorrhizal symbiosis. Mycorrhiza. 2001;11:3-42.

35. Berlin J, Dewick PM, Barz W, Grisebach H. Biosynthesis of coumestrol in Phaseolus aureus. Phytochemistry. 1972;11:1689-93.

36. Dewick PM, Barz W, Grisebach H. Biosynthesis of coumestrol in Phaseolus aureus. Phytochemistry. 1970;9:775-83.

37. Suzuki H, Takahashi S, Watanabe R, Fukushima Y, Fujita N, Noguchi A, et al. An Isoflavone Conjugate-hydrolyzing $\beta$-Glucosidase from the Roots of Soybean (Glycine max) Seedlings: purification, gene cloning, phylogenetics, and cellular localization. J Biol Chem. 2006;281:30251-9.

38. Yang J, Isabel Ordiz M, Jaworski JG, Beachy RN. Induced accumulation of cuticular waxes enhances drought tolerance in Arabidopsis by changes in development of stomata. Plant Physiol Biochem. 2011;49:1448-55.

39. Hamanishi ET, Thomas BR, Campbell MM. Drought induces alterations in the stomatal development program in Populus. J Exp Bot. 2012;63:4959-71.

40. Tripathi P, Rabara RC, Shen QJ, Rushton PJ. Transcriptomics analyses of soybean leaf and root samples during water-deficit. Genomics Data. 2015:5:164-6.

41. Xu Z, Zhou G. Responses of leaf stomatal density to water status and its relationship with photosynthesis in a grass. J Expt Bot. 2008;59:3317-25.

42. Du Z, Zhou X, Ling Y, Zhang Z, Su Z. agriGO: a GO analysis toolkit for the agricultural community. Nucleic Acids Res. 2010;38:W64-70

43. Yi X, Du Z, Su Z. PlantGSEA: a gene set enrichment analysis toolkit for plant community. Nucleic Acids Res. 2013;41:W98-103.

44. Tripathi P, Rabara RC, Langum TJ, Boken AK, Rushton DL, Boomsma DD, et al. The WRKY transcription factor family in Brachypodium distachyon. BMC Genomics. 2012;13:270.
45. Craig R, Cortens JC, Fenyo D, Beavis RC. Using annotated peptide mass spectrum libraries for protein identification. J Proteome Res. 2006:5:843-9.

46. Rappsilber J, Ishihama Y, Mann M. Stop and go extraction tips for matrixassisted laser desorption/ionization, nanoelectrospray, and LC/MS sample pretreatment in proteomics. Anal Chem. 2003;75:663-70.

47. Beavis RC. Using the global proteome machine for protein identification. Methods Mol Biol. 2006;328:217-28.

48. Bjornson RD, Carriero NJ, Colangelo C, Shifman M, Cheung KH, Miller PL, et al. X!!Tandem, an improved method for running X!tandem in parallel on collections of commodity computers. J Proteome Res. 2008;7:293-9.

49. Li Y, Chi H, Wang LH, Wang HP, Fu Y, Yuan ZF, et al. Speeding up tandem mass spectrometry based database searching by peptide and spectrum indexing. Rapid Commun Mass Spectrom. 2010;24:807-14.

50. MacLean B, Eng JK, Beavis RC, Mclntosh M. General framework for developing and evaluating database scoring algorithms using the TANDEM search engine. Bioinformatics. 2006;22:2830-2.

51. Geer LY, Markey SP, Kowalak JA, Wagner L, Xu M, Maynard DM, et al. Open mass spectrometry search algorithm. J Proteome Res. 2004;3:958-64.

52. Evans AM, DeHaven CD, Barrett T, Mitchell M, Milgram E. Integrated, nontargeted ultrahigh performance liquid chromatography/electrospray ionization tandem mass spectrometry platform for the identification and relative quantification of the small-molecule complement of biological systems. Anal Chem. 2009;81:6656-67.

53. Goodstein DM, Shu S, Howson R, Neupane R, Hayes RD, Fazo J, et al. Phytozome: a comparative platform for green plant genomics. Nucleic Acids Res. 2012:40:D1178-86.

54. Hernandez-Garcia CM, Bouchard RA, Rushton PJ, Jones ML, Chen X, Timko MP, et al. High level transgenic expression of soybean (Glycine max) GmERF and Gmubi gene promoters isolated by a novel promoter analysis pipeline. BMC Plant Biol. 2010;10:237.

55. Collier R, Fuchs B, Walter N, Kevin Lutke W, Taylor CG. Ex vitro composite plants: an inexpensive, rapid method for root biology. Plant J. 2005;43:449-57.

56. Abramoff, M.D., Magalhães, P.J. and Ram, S.J. (2004) Image Processing with ImageJ. Biophotonics International July 2004.

\section{Submit your next manuscript to BioMed Central and we will help you at every step:}

- We accept pre-submission inquiries

- Our selector tool helps you to find the most relevant journal

- We provide round the clock customer support

- Convenient online submission

- Thorough peer review

- Inclusion in PubMed and all major indexing services

- Maximum visibility for your research

Submit your manuscript at www.biomedcentral.com/submit
Ciomed Central 